\title{
Main Applications and Recent Research Progresses of Additive Manufacturing in Dentistry
}

\author{
Gan Huang $\mathbb{D}^{1},{ }^{1}$ Libo Wu, ${ }^{2}$ Jie Hu, ${ }^{1}$ Xiongming Zhou, ${ }^{1}$ Fei He, ${ }^{1}$ Li Wan, ${ }^{1}$ \\ and Shu-Ting Pan $\mathbb{D}^{1}$ \\ ${ }^{1}$ Department of Stomatology, The First Affiliated Hospital of Nanchang University, Nanchang, 330006 Jiangxi, China \\ ${ }^{2}$ Department of Stomatology, The Third Hospital of Nanchang, Nanchang, 330000 Jiangxi, China \\ Correspondence should be addressed to Shu-Ting Pan; panshuting314@126.com
}

Received 20 January 2021; Revised 16 December 2021; Accepted 28 January 2022; Published 24 February 2022

Academic Editor: Fernanda Faot

Copyright (c) 2022 Gan Huang et al. This is an open access article distributed under the Creative Commons Attribution License, which permits unrestricted use, distribution, and reproduction in any medium, provided the original work is properly cited.

\begin{abstract}
In recent ten years, with the fast development of digital and engineering manufacturing technology, additive manufacturing has already been more and more widely used in the field of dentistry, from the first personalized surgical guides to the latest personalized restoration crowns and root implants. In particular, the bioprinting of teeth and tissue is of great potential to realize organ regeneration and finally improve the life quality. In this review paper, we firstly presented the workflow of additive manufacturing technology. Then, we summarized the main applications and recent research progresses of additive manufacturing in dentistry. Lastly, we sketched out some challenges and future directions of additive manufacturing technology in dentistry.
\end{abstract}

\section{Introduction}

Additive manufacturing (AM) is commonly called threedimensional (3D) printing technology. There are other more synonyms of AM in the research literature, such as additive fabrication, additive processes, additive techniques, additive layer manufacturing, layer manufacturing, freeform fabrication, rapid manufacturing, direct digital manufacturing, and rapid prototyping $[1,2]$. The American Society for Testing and Materials (ASTM) has defined AM as "a process of joining materials to make objects from 3D model data, usually layer upon layer, as opposed to subtractive manufacturing methodologies" [2]. The International Organization for Standardization (ISO), another globally recognized leader in the arena of international standards, declares that the definition of AM shall be in accordance with the ASTM F2792 standard [3, 4]. AM technology has been developed for over 40 years and has reached a maturity level that can be converted into commercial applications in many industries including automotive, aerospace, consumer products, and biomedical engineering [5, 6]. AM technology is based on the data of a $3 \mathrm{D}$ mathematical model and continuous layered printing technologies [7]. Unlike a subtractive manufacturing process, AM can directly produce complex three-dimensional structures with improved manufacturing accuracy, simplified production process, economized materials and human resources, shortened production time, and improved production efficiency and can be utilized in precision medicine to achieve personalized needs [7-10]. In the field of dentistry, AM technology has been more and more widely used and researched concerning maxillofacial surgery, denture implantation, prosthodontics, and orthodontics, from the production of the personalized surgical guides to the fabrication of maxillofacial alternatives, dental implant, and the manufacture of internal crowns, skeletons for implants and dental restorations, etc. [11-15]. The application of AM technology has led to the development of dentistry from traditional pure empirical methods to digitization and precision [16]. The widespread use of cone-beam CT (CBCT) can rebuild three-dimensional maxillofacial and dental anatomy which significantly improves the quality of diagnosis and treatment and expedites the development of AM in dentistry [17]. Besides, bioprinting using AM which incorporates 
active ingredients such as cells, matrix, and growth factors has shown amazing development potential in the field of tooth, jawbone, and periodontal tissue regeneration. This review surveys the data, materials, and methods in AM technology that are helping to enable improvement in precision dentistry. Application of these additive manufactured platforms will also be described to provide a historical perspective while focusing on the state of the art in dentistry.

\section{Historical Evolution of AM Technology}

The germ of additive manufacturing technology originated from the sculpture art of Western Europe in the 18th century and has received attention in North America in the 19th century. With the development of computer and network technology in the 20th century, 3D printing technology was really born. And the evolution of AM technology has tremendously accelerated at present (Figure 1). In 1980s, American engineer Charles Hull patented the first 3D printing device and technology named as stereolithography $[18,19]$; in 1986, Charles Hull developed the first commercial 3D printing machine, the SLA-1; in 1989, Carl Deckard patented the powder-based selective laser sintering (SLS) method where the powdered material is melted and refused by a laser beam [20].

In 1991, human anatomy models produced by stereolithography were first applied in a maxillofacial surgery clinic in Vienna; in 1992, Scott Crump invented the fused deposition modeling (FDM) method to print a 3D structure [21]; in 1993, Massachusetts Institute of Technology (MIT) obtained the patent for 3D printing technology; in 1995, the United States ZCorp company got the sole authorization from MIT and started to develop 3D printers.

In 2003, Sweden Arcam AB company first introduced commercial electron beam melting (EBM) equipment in the world; in September 2004, the first international workshop on bioprinting was held at the University of Manchester [22]; in 2005, the first high-definition color 3D printer Spectrum Z510 on the market was successfully developed by ZCorp; in 2007, the first 3D bioprinting company Organovo was founded [23]; in November 2010, the world 's first printed car Urbee came out; in June 2011, the world's first 3D-printed bikini was released; in July 2011, British researchers developed the world's first 3D chocolate printer; in August 2011, engineers from the University of Southampton developed the world's first 3D-printed aircraft; in November 2012, Scottish scientists used human cells to print artificial liver tissue with a 3D printer for the first time [24]; in 2016, Germany Biotronik company realized the first clinically proven biodegradable magnesium-based scaffold for coronary artery lesion in the world [25]. With the advent of new materials and improvement of AM technology, tissue engineering will be developed rapidly.

\section{Workflow of AM Technology}

Just as illustrated in Figure 2, the main workflow of AM technology comprises data collection, data processing, material selection, and the final printing procedure. Data collec- tion and processing are the fundamental steps and often used to establish a digital model via various types of CAD software. And the digital model should be solidified by the optimal material and corresponding manufacturing procedure. On the other hand, the selection of a certain material and printing procedure is dependent on the application or research purpose.

3.1. Data Collection. The collection of $3 \mathrm{D}$ data is an important step in model making, as low-resolution images can lead to discrepancy between the generated model and actual anatomy [26]. At present, there are four common methods: software design, optical scanning, mechanical scanning, and radiological scanning. Models designed using design software do not have to be constrained to the size of real objects and are convenient for calculation, analysis, modification, and editing [27]. Optical scanning commonly applies three-dimensional laser scanning, projection raster measurement, moiré fringe method, or stereo photography. It has a higher scanning rate and better accuracy, but the complex shape will make the scanning a blind spot, and errors will occur in the scanned data [28]. Handheld optical scanning showed a low geometric assessment for imaging a complete denture form [29]. With the increase in the freedom degree of the mechanical probe, the scanning blind area will be reduced [30]. With the development of computer tomography (CT) and nuclear magnetic resonance (MRI) technology, radiological diagnosis has become less invasive and more accurate [31]. The high-resolution 3D image data can be obtained within seconds, making radiological scanning an ideal method for 3D data acquisition [32]. CT data reconstructed from slice thicknesses of $0.5-1 \mathrm{~mm}$ are be suitable for maxillofacial surgery models [33]. Still and all, the potential risks of ionizing radiation remain a concern [34]. Despite the fact that MRI offers a nonionizing alternative to CT, simple thresholding-based segmentation is unsuitable due to the overlapping pixel values of bone, soft tissue, and air [35]. To solve this problem, Eley et al. developed a semi- and fully automated segmentation algorithm utilizing short echo time (ZTE) for the craniofacial skeleton. This technique is transferrable to a routinely used non-bone-specific sequence (FIESTA-C) imaging which offers enhanced resolution and reduced acquisition time $[36,37]$.

3.2. Data Processing. A special high-performance computer is generally used to process the obtained $3 \mathrm{D}$ data into the $3 \mathrm{D}$ reconstruction software. Segmentation is a commonly used step in medical applications to isolate the area of interest within the data set. The scanned data in terms of DICOM (Digital Imaging and Communications in Medicine) format is imported into the software such as Mimics, Geomagic, ProPlan, and Simplant. There are some differences between the features of software packages particularly in the fine and thin areas of osseous structures; it is essential to understand the features of software package for the intended purpose [38]. Generally, these types of software can read the DICOM data and rebuild the 3D model $[39,40]$. The threshold tool allows one to retain or remove areas of interest according to density values of tissue types. Another tool 


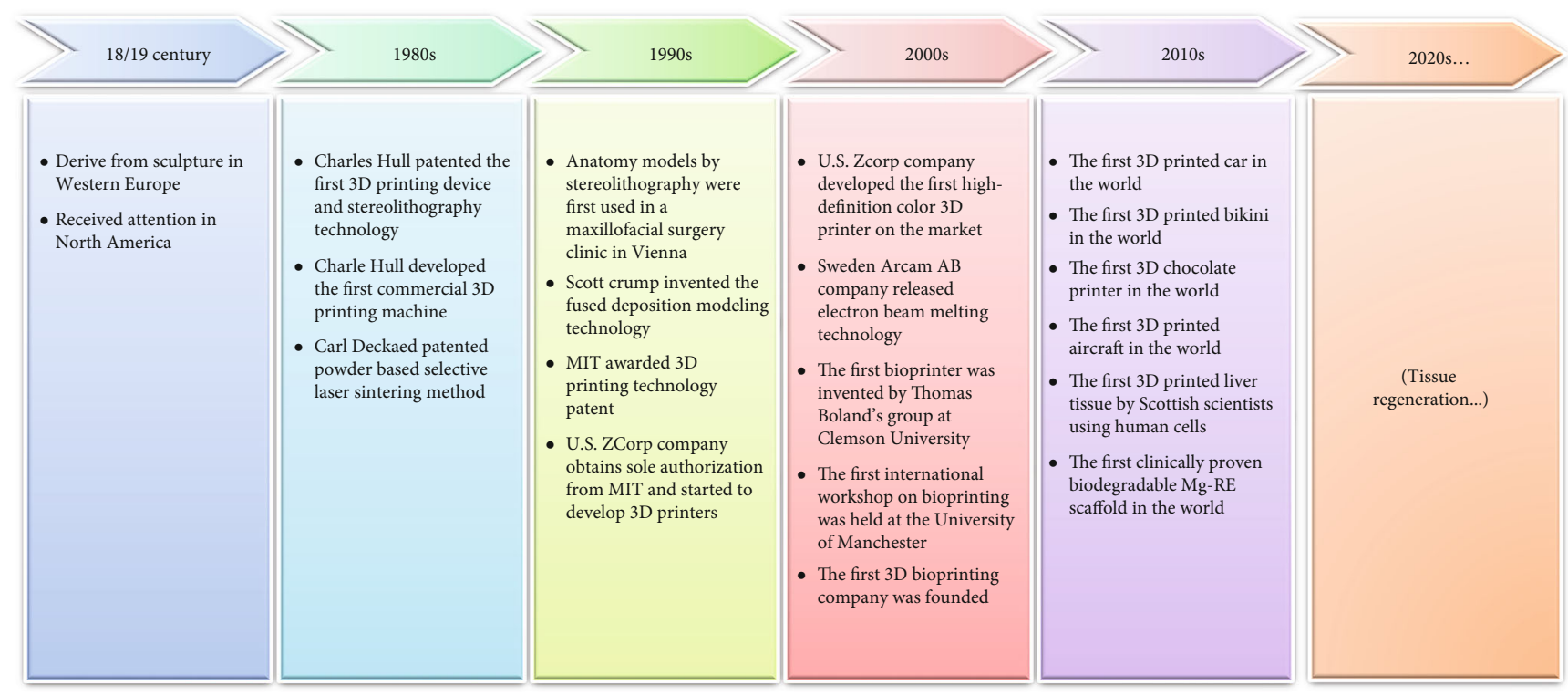

FIGURE 1: Historical evolution of additive manufacturing.

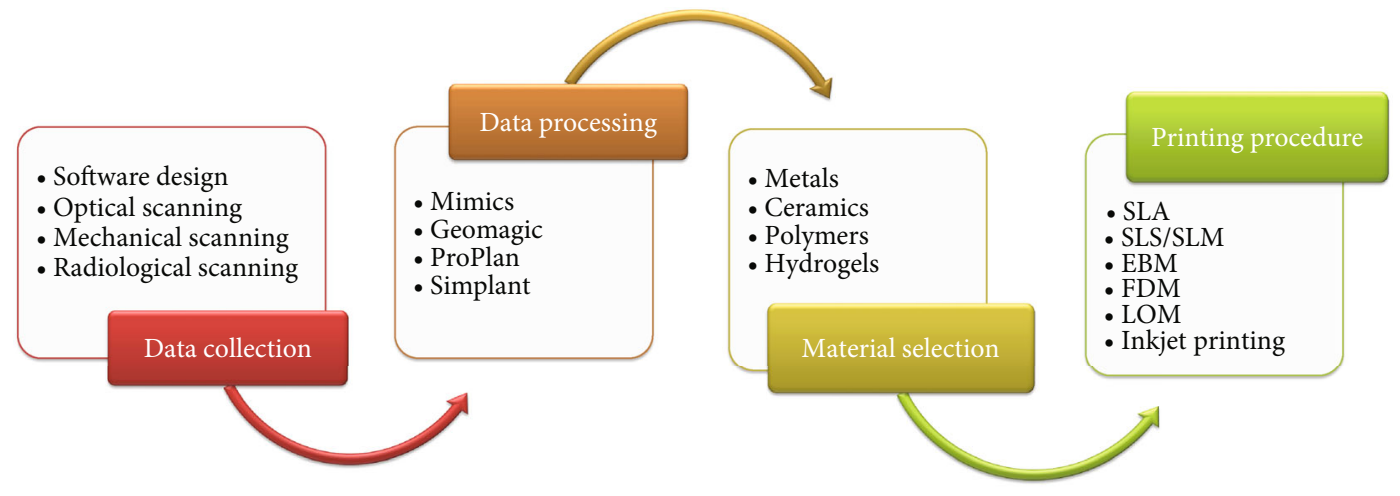

FIGURE 2: Workflow of additive manufacturing.

for segmenting is seed-based region growing which employs a starting point or seed and sets voxel density parameters. Additional voxels which meet the defined density criteria are then added to the seed [41]. After segmentation, volumetric data are converting into $3 \mathrm{D}$ triangular mesh surfaces with the help of automated surface rendering tools. The quantity of triangle "fragments" is positively related to the model accuracy and graph smoothness [26]. The process of segmentation and mesh generation may bring about significant inaccuracies between the original DICOM data and the final 3D generated model. To ensure a true anatomical presentation, it is critical to compare the region of interest with the original DICOM data after every major step [42]. Then, the reconstructed data is saved as the STL (Surface Tessellation Language) format. Finally, the STL data can be recognized and processed by the 3D printer [16].

\subsection{Material Selection}

3.3.1. Metals. Many metals and metal alloys are available, but only a few are safe to implant into people. For biomedical applications, metal products are required to own good mechanical properties, biocompatibility, and corrosion resistance properties [43]. Biocompatibility of a metallic material guarantees the desired function of the material without inducing harmful local or systemic effects on the surrounding tissue. Currently, metallic materials including stainless steel, cobalt chromium alloy, and titanium and titanium alloy are biologically compatible and can be used for dental applications [44]. In the 1920s, stainless steels (SS) are widely used due to the properties of corrosion resistance, enhanced strength, and bargain price [45]. SS 316 and 316 with low carbon content (L) are the most commonly used stainless steel alloys in the field of maxillofacial reconstruction [46]. These alloys contain chromium, molybdenum, and nickel yielding corrosion resistance [47]. However, these stainless steel alloys are not suitable for manufacturing permanent implants due to their low mechanical properties [48]. In the 1930s, cobalt chromium (Co-Cr) alloys, possessing better biocompatibility and wear resistance and higher hardness than SS 316, have been applied successfully for orthodontics and prosthodontics in dentistry [49].

Titanium (Ti) and titanium alloy materials have the advantages of small density, high accuracy and large 
mechanical strength, and good biocompatibility. Porous titanium and titanium alloys have been successfully used in dental application since the end of the 1960s [50]. Moreover, they are regarded as ideal 3D-printing metal materials [51] and have been widely used, especially in the reconstruction of oral and maxillofacial [52] and manufacturing of a dental implant [53]. Due to some defects of pure titanium, for example, the strength of pure titanium is not as great as that of titanium alloys, and the elastic modulus of pure titanium is higher than that of bone tissue, which can easily lead to incompatible mechanical stress between titanium implants and bone. Many researchers have tried various ways to improve the performance of pure titanium, such as adding a coating on its surface or oxidized pure titanium surface [54-56]. Nonstochastic geometry titanium with a periodic repetition of lattice structures shows better mechanical properties and enhanced osseointegration [57]. Traini et al. formed a gradient titanium- 6 aluminium- 4 vanadium (Ti$6 \mathrm{Al}-4 \mathrm{~V})$ titanium alloy porous dental implant, which has more optimized physical and chemical properties. The tensile strength, section shrinkage, and elongation are up to AMs4999 (standards on 3D-printed titanium alloys issued by ASTM) [58]. The elastic modulus of the sintered titanium core is similar to that of machined titanium, while the elastic modulus of the porous layer on the surface of this laser sintered titanium alloy implant is reduced thus similar to that of cortical bone. It is beneficial to the long-term stability of the implant [58]. After heat treatment, the mechanical strength of Ti-6Al-4V can be increased up to $50 \%$ without affecting Young's modulus [59]. Not only can the classical Ti-6Al-4V alloy be printed but also the second generation of titanium alloys, such as Ti-12Mo-6Zr-2Fe, Ti-15Mo5Zr-3Al, To-13Nb-13Zr, and Ti-15Sn-4Nb-2Ta-0.2Pd, has been developed for biomedical printing [60]. These titanium alloys containing $\mathrm{Nb}, \mathrm{Ta}$, and $\operatorname{Zr}$ ( $\beta$ stabilizing elements) have low moduli of elasticity and spare toxicity of the aluminium or vanadium [61].

The metallic implants can be fabricated using AM technologies which are powder bed fusion processes. Selective laser sintering (SLS), selective laser melting (SLM), and electron beam melting (EBM) are the most established methods that rely on local fusion of metal particles to form a solid material [62]. Metal powders used in AM need to be spherical and have a stringent particle size distribution to achieve good packing effect [44]. Compared with casting and milling techniques, SLS-fabricated CoCrMo dental alloys had better mechanical properties and less dissolution of metal ions [63]. An engineered porous structure of metallic alloys by AM technology helps to match the stiffness of the implant with that of the natural bone [64]. Thus, the stress shielding effect can be addressed. Moreover, the porosity also facilitates bone cell growth, creating solid osseointegration between the bone and the implant [65].

The properties of the printed metal materials vary across the printing methods. For example, Ti-6Al-4V printed via SLS exhibits an $\alpha$ martensitic microstructure, while Ti-6Al$4 \mathrm{~V}$ printed via EBM shows a needle-like $\alpha+\beta$ Widmanstatten microstructure [66]. The mechanical properties of SLSprinted $\mathrm{Ti}-6 \mathrm{Al}-4 \mathrm{~V}$ are anisotropic, different from the isotro- pic mechanical properties of EBM-printed Ti-6Al-4V. Besides, the residual stress and porosity of SLS-printed Ti$6 \mathrm{Al}-4 \mathrm{~V}$ are larger than those of EBM-printed Ti-6Al-4V [66]. One step worth mentioning is the post-AM heat and surface treatments. By this, AM porous metal materials can obtain improved microstructure and mechanical properties $[67,68]$. Hot isostatic pressing, combining high temperature with high pressure level, can be applied to close the cavernous defects generated by the AM process [67, 69]. Sand blasting and chemical etching are used to remove unmolten powder thus to improve the surface properties of AM porous implants before using them in vivo $[67,69]$.

3.3.2. Ceramics. In dentistry, ceramic materials are required to have aesthetics and biocompatibility as well as low density, high strength, high hardness, high temperature resistance, corrosion resistance, and good physical and chemical properties. Ceramics such as zirconia and alumina are currently used in artificial dental bridges and crowns. Zirconia can be also used in dental implants which display comparable osseointegration with titanium [70]. When zirconia ceramics are fabricated by cutting technology, a lot of materials will be cut off resulting in waste and high price of the all-ceramic crown. This craft process may also cause internal cracks by cutting forces in the denture. The AM technology in fabricating zirconia ceramic dentures can reach more than $90 \%$ of material utilization, lower the price, and reduce environmental pollution [71]. Noteworthy, 3Dprinted zirconia can achieve the bioimitability such as hardness by printing special internal structures [72]. The AM procedure for fabricating zirconia is mainly based on the laser sintering method, but there are some problems such as low density and forming efficiency and surface cracks [73]. Stereolithographic ceramic manufacturing has good surface quality and controllability of structural accuracy $[74,75]$ and quickly becomes a research hotspot. At present, there are still some problems in the AM process of zirconia materials, such as large internal stress, cracking after sintering, and volume shrinkage, which may affect its mechanical properties and clinical suitability. Ceramic materials and their fabricating technology still need further investigation.

3.3.3. Polymers. Polymer materials have become the basic mature printing material in the field of 3D printing. In dentistry, polylactic acid (PLA), polycaprolactone (PCL), and polyetheretherketone $(\mathrm{PEEK})$ are relatively common $3 \mathrm{D}$ printing materials. PLA is an environmentally friendly material with good biodegradability. It can be completely degraded by microorganisms in nature under specific conditions and eventually generate carbon dioxide and water, which will not cause environmental pollution and is very beneficial to environmental protection. It also has translucency and gloss texture, making it an ideal material for 3D printing in the field of dentistry. A 3D-printed scaffold using a blend of PCL and gelatin has superior mechanical flexibility and softness which could be suitable for soft tissue engineering such as rhinoplasty. Human adipose-derived stem cell was cultured on this scaffold and showed increased cartilage differentiation and tissue formation [76]. 
Polyetheretherketone (PEEK) is a thermoplastic polymer. PEEK material has a similar modulus of elasticity to human bones, and the stress of the skull after repair is complete; X-ray transmission performance is good, no metal artifacts are generated, it does not affect medical images, and it is convenient to detect postoperative recovery; currently, PEEK is used to manufacture denture parts. The Oxford Performance Materials company used PEKK to print craniofacial bone repair patch which has been approved by the US Food and Drug Administration (FDA).

3.3.4. Hydrogels. The hydrogels, typical and commonly used materials in bioprinting, have a 3D network structure with hydrophilic polymer chains, and the water content is $90 \%$ to $99 \%$, which contributes to effective oxygen and substance exchange. In the past few decades, hydrogels have achieved unprecedented development in the construction of tissue engineering scaffolds and drug carrier due to their high biocompatibility, low immunogenicity, and adjustable physical and chemical properties [77, 78]. The hydrogel multimer system can provide a good matrix for cell transplantation and differentiation, endogenous regeneration, bioremediation, wound healing, and continuous drug delivery, while its three-dimensional network system can simulate the microstructure of the original extracellular matrix and provide living ecological conditions for cell survival $[79,80]$. However, at present, the hydrogel prepared by 3D drawing organisms has low hardness, which may lead to structural collapse or the complexity of shape restriction. To optimize the structure and function of hydrogel, many efforts have been made. Gelatin methacryloyl- (GelMA-) based hydrogel can undergo photopolymerization of methacryloyl substituents to generate covalently crosslinked hydrogels which are very suitable for manufacturing biological constructs with unique patterns and morphologies [81, 82]. Hyaluronic acid (HA), a water-soluble glycosaminoglycan, has been formulated into hydrogels [83]. Methacrylates and acrylates can modify HA via amide, carboxylate, and dydroxyl functionalities [84]. Methacrylated HA has been applied in tissue engineering scaffolds as well as the bioprinting of cell-laden scaffolds [82, 85]. Moreover, to improve the reliability and printing resolution, hydrogel can be deposited into a granular support bath with small, uniform, and spherical microparticles $[86,87]$.

3.4. Printing Procedure. The printing procedure applied in dentistry mainly comprises stereolithography (SLA), laserbased printing, electron beam melting (EBM), fused deposition modeling (FDM), laminated object manufacturing (LOM), and inkjet printing (IJP). The merits and schematic diagrams of these AM technologies are shown in Table 1 and Figure 3, respectively.

3.4.1. Stereolithography. Stereolithography (SLA) uses a photopolymer to cure by ultraviolet or visible light irradiation. The material of the SLA process is photosensitive polymers which can rapidly polymerize under the irradiation of specific wavelength and intensity ultraviolet light, thereby transferring from liquid to solid with high accuracy. SLA technology has the characteristics of rapid fabrication time, high precision, and stable performance which can be applied to form complex architectures [88]. Due to the limitation of the material, this printing method needs a supporting structure. The manufactured products are generally brittle and easily broken and require a strict storage [89]. The ideal SLA system depends on the careful calibration of light type and intensity, photoinitiator/photoabsorber sensitivities and concentration, and material concentration and reactivity [90]. This SLA printing technology is widely used in restoration of defected teeth, complete denture base, resin crown, dowel crown, implant guide, and tooth root canal model.

3.4.2. Laser-Based Printing. Selective laser sintering (SLS) and selective laser melting (SLM) technology can be vastly used in processing small particles of metal, polymer, and ceramic materials, including titanium and titanium alloy powder, cobalt chrome, stainless steel, nylon powder, and elastomers. The advantages are high good mechanical property, good accuracy, and high material utilization rate. The disadvantages are easy to produce spherification which affects the product quality [91]. For metal and metal alloys, SLS is also described as direct laser metal sintering (DLMS) or direct laser metal formation (DLMF) which is commonly used method in the maxillofacial and denture implant.

SLM uses laser to melt metal powder which is a physicalchemical metallurgical change. This technology overcomes the overcomplicated SLS process. The manufactured products have better compactness and higher performance but are prone to spheroidization which requires continuous improvement and optimization of this procedure [92]. SLS and SLM are mainly used in implant guide, implant, and alternative of large jawbone defects.

3.4.3. Electron Beam Melting. Electron beam melting (EBM) is a new type of direct manufacturing technology for metal parts developed in recent years. It is a process of selectively melting metal powders by high-energy electron beams and depositing them layer by layer until the required metal parts are manufactured. EBM technology can easily, quickly, and accurately complete the manufacture of extremely complex morphological parts and can especially form a complex three-dimensional interconnected pore structure, which provides structural conditions for orthopedic implants to induce bone cell ingrowth. Implants have unique advantages and become an important way to meet individual needs [92].

3.4.4. Fused Deposition Modeling. Fused deposition modeling (FDM) is to eject molten thermoplastic material such as polycarbonate or eutectic metal powder and immediately solidify it. The material filaments are heated in the hot melt nozzle through the transmission mechanism, then extruded and solidified through the nozzle, and finally formed layer upon layer. The molding speed is fast and relatively accurate, without expensive laser sintering equipment, and the price is relatively low. This kind of materials is mostly used in oral implant prostheses [93]. Polylactic acid composite materials (such as hydroxyapatite/polylactic acid) can be selected to 


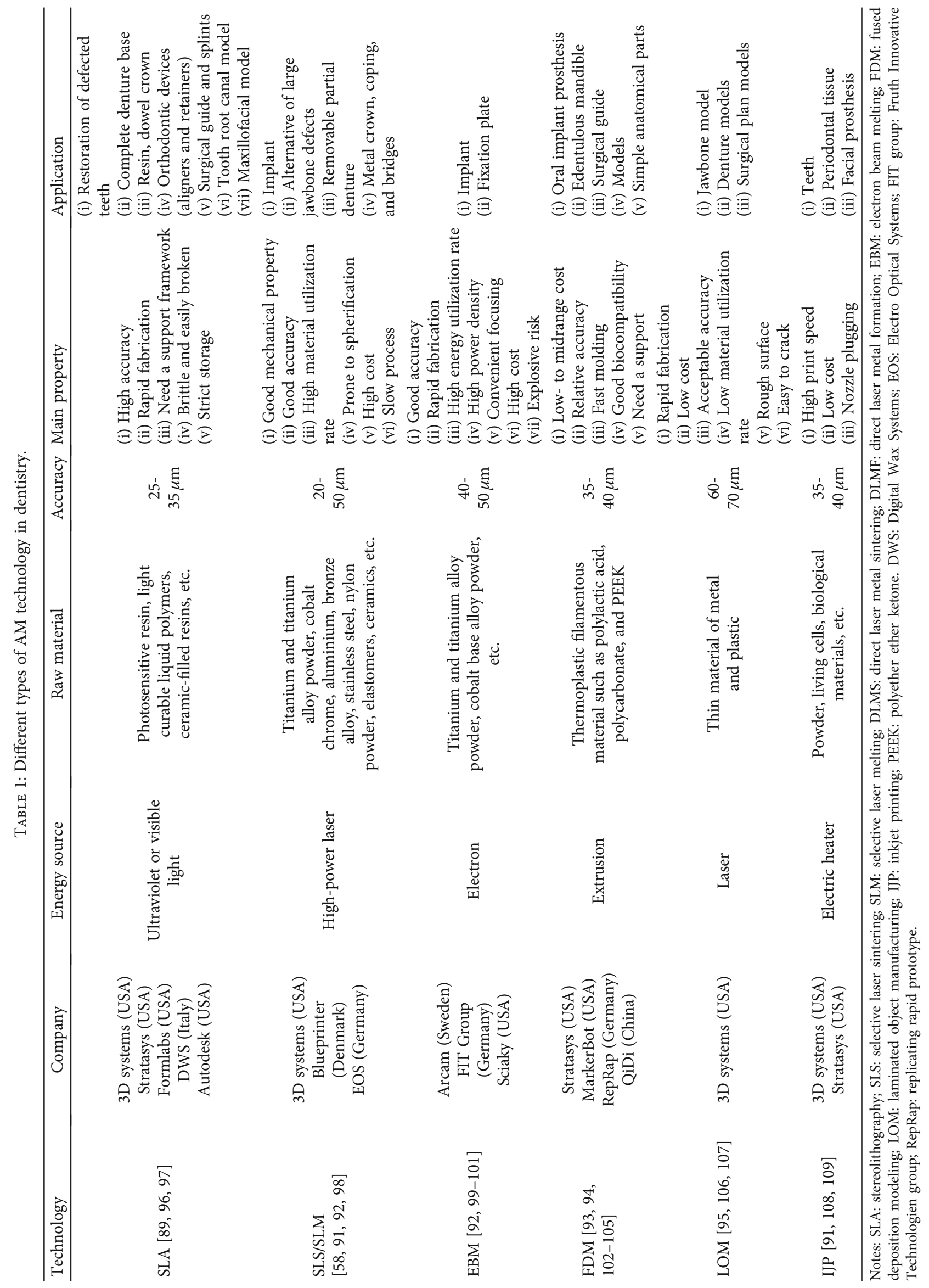




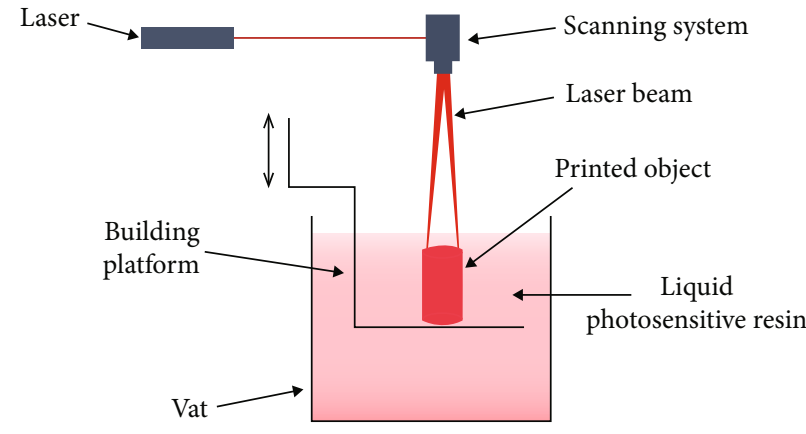

(a)

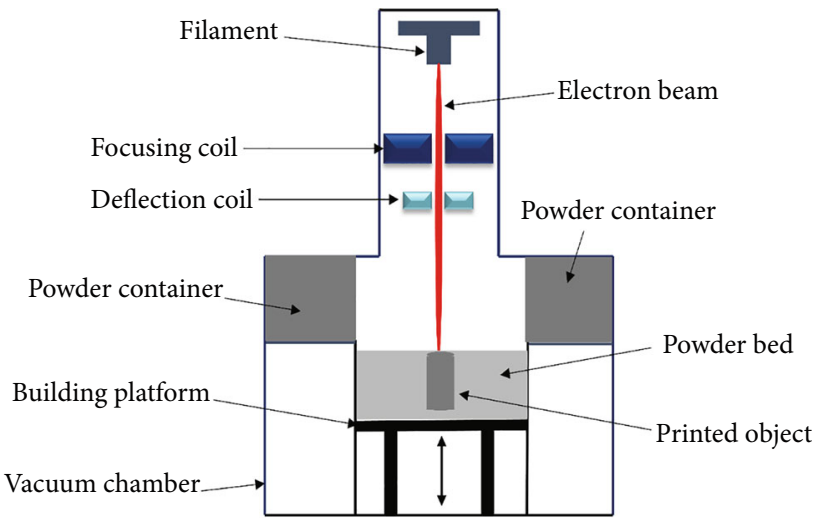

(c)

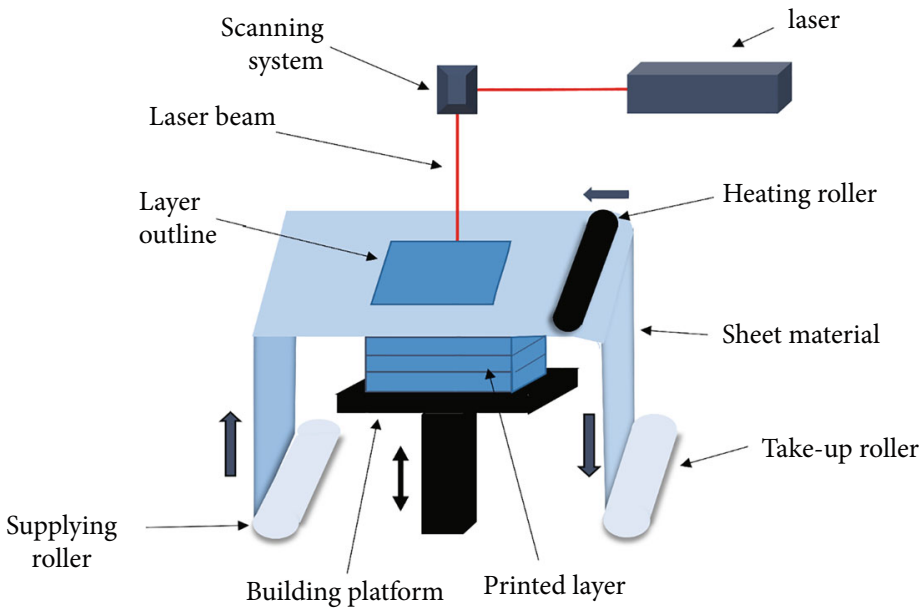

(e)

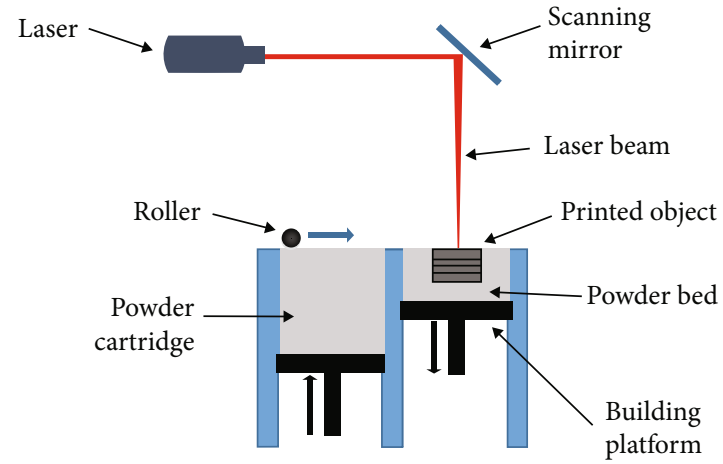

(b)

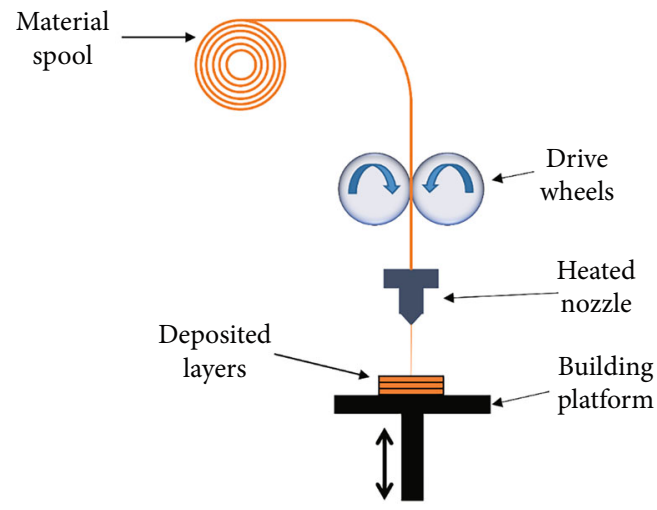

(d)

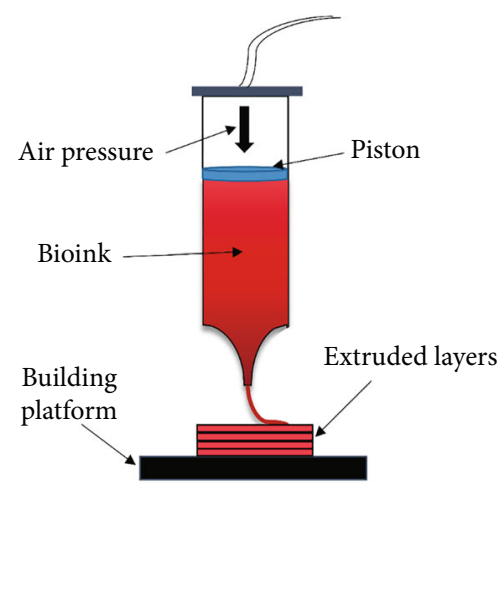

(f)

FIGURE 3: The schematic diagrams of various AM procedures including SLA (a), laser-based printing (b), EBM (c), FDM (d), LOM (e), and inkjet printing (f).

induce the adhesion of osteoblasts in the alveolar socket to the prosthesis [94]. Compared with traditional oral prostheses, this technique significantly saves the treatment cost, shortens the operation time, and improves the strength of the prosthesis

3.4.5. Laminated Object Manufacturing. Laminated object manufacturing (LOM) is to use glue to glue paper or plastic film together and then use laser to shape. The thin material of LOM adheres layer by layer under the action of hot melt adhesive. The advantage of this technology is that the price of raw materials is relatively low, and the accuracy is acceptable, but the surface of the manufactured product is relatively rough with obvious ladder patterns and easy to crack, so this technology is usually used to make jawbone and denture models and formulate comprehensive and effective surgical plan models [95].

3.4.6. Inkjet Printing. Inkjet printing (IJP) can be used to print living cells and biological materials to construct a 


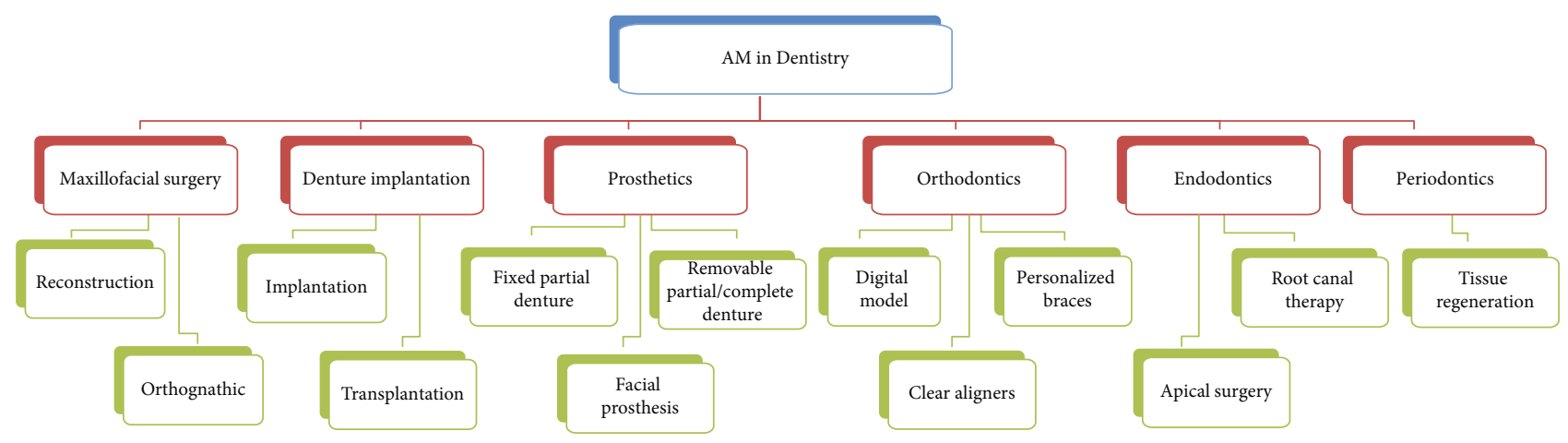

FIgURE 4: Main applications of additive manufacturing in dentistry.

three-dimensional biological scaffold containing different tissues, even living organs. The mixture of hydrogels and cells are distributed into series of droplets using thermally driven nozzle. By layers of printing, three-dimensional structures containing cells can be formed. IJP technology has many advantages such as high resolution, reproducibility, inexpensiveness, and ease of use. Thermally driven IJP is of fast printing speed, and the printing nozzles generate bubbles through local resistance heating, squeezing the liquid in the nozzle to obtain droplets. However, its performance in droplet direction, uniformity, and size control is not satisfactory, and the thermal stress, nozzle clogging, cell exposure, and other problems generated during the ejection process are often detrimental to printing influences. And the shear force generated by inkjet $3 \mathrm{D}$ printing is easy to cause loss of cells. Therefore, improving the survival rate of inkjet $3 \mathrm{D}$ printing cells and optimizing the printing process still face challenges [91].

\section{Applications and Recent Research Progresses of AM Technology in Dentistry}

AM technology is widely used in the biomedical field due to its high precision and personalized characteristics [110]. FDA has cleared some 3D-printed devices for clinical use including orthopedics devices, surgical guides, and dental bridges [111, 112]. In dentistry, the main applications and research directions of 3D printing include the following: three-dimensional stereoscopic image software combined with prototype models for anatomy teaching guidance $[113,114]$, preoperative planning and drills [115], prognosis analysis and judgment [116], personalized treatment equipment, assistive devices and implants including personalized orthodontic brackets and accessories $[117,118]$, restorations [119], trays [96], implants and surgical guides [120,121], and bioactive materials combined with living cells and growth factors to print tissues and organs with bioactive functions $[122,123]$ (Figure 4). Nevertheless, the bioprinting is still at the stage of printing biological scaffolds and needed further exploitation to mimic complex structure and function of natural tissues in the human body [124].

\subsection{AM Technology in Maxillofacial Surgery (Table 2)}

4.1.1. Reconstruction. Maxillofacial trauma and tumors can cause maxillofacial fractures and bone defects, and restoring the normal anatomy of the maxillofacial region and lan- guage function is of great significance to improve the quality of life. In the 1990s, scholars began to try to apply 3D printing technology to the preoperative evaluation of maxillofacial surgery, formulating surgical plans and simulations. Compared with traditional milling models, the stereolithographic 3D models have much higher accuracy [125]. And the application of stereolithographic technology has improved the diagnostic accuracy by $29.60 \%$ and the operation accuracy by $36.23 \%$ and shortened the operation time by $17.63 \%$ [126]. In 2012, the Institute of Biomedical Research at Hasselt University in Belgium used 3D printing technology to make a pair of titanium alloy mandibles for an 83-year-old patient. The patient recovered language and swallowing function one day after surgery. Melville et al. and Takano et al. used the CAD/CAM technology to create a model for fibular flap transplantation for partial maxilla resection and used the model to create a device for guiding the position of the mandible excision and a titanium plate for fibular flap fixation. This procedure shortened surgery time and improved safety, function, and esthetic outcomes [127, 128]. Haider et al. demonstrated a feasible in-house virtual surgical plan (VSP) and 3D-printed cutting guides in maxillofacial reconstruction. 19 patients with maxillofacial tumors undergoing microvascular bone reconstruction were managed by this technique. The average time for VSP and fabrication of cutting guides was 158 minutes. The average cost was $\$ 18.01$ Canadian dollars [129]. This in-house VSP and 3D printing are operable for the surgeon and can benefit patients. Park et al. [130] have recently introduced a novel $3 \mathrm{D}$-printed Ti implant to restore huge mandibular defect caused by osteoradionecrosis (Figure 5(a)). In order to rehabilitate mastication, three dental implant fixtures were installed in this mandibular implant during the surgery (Figures 5(b) and 5(c)). Moreover, customized temporomandibular joint (TMJ) prosthesis has been employed for the treatment of end-stage TMJ osteoarthrosis (Figures 5(d)-5(f)). Twelve patients recruited in this clinic trial reported an average of $90.7 \%$ decrease in pain, $70.8 \%$ improvement in mandible function, $79.9 \%$ improvement in diet, and $32.8 \%$ increase in maximal interincisal opening (MIO) postsurgery 1 year. The anatomical structure of this TMJ prosthesis can match that of the individual patient [131].

4.1.2. Orthognathic Surgery. Orthognathic surgery is commonly applied to treat skeletal malocclusion which severely affects the occlusion function and the facial features of patients. 


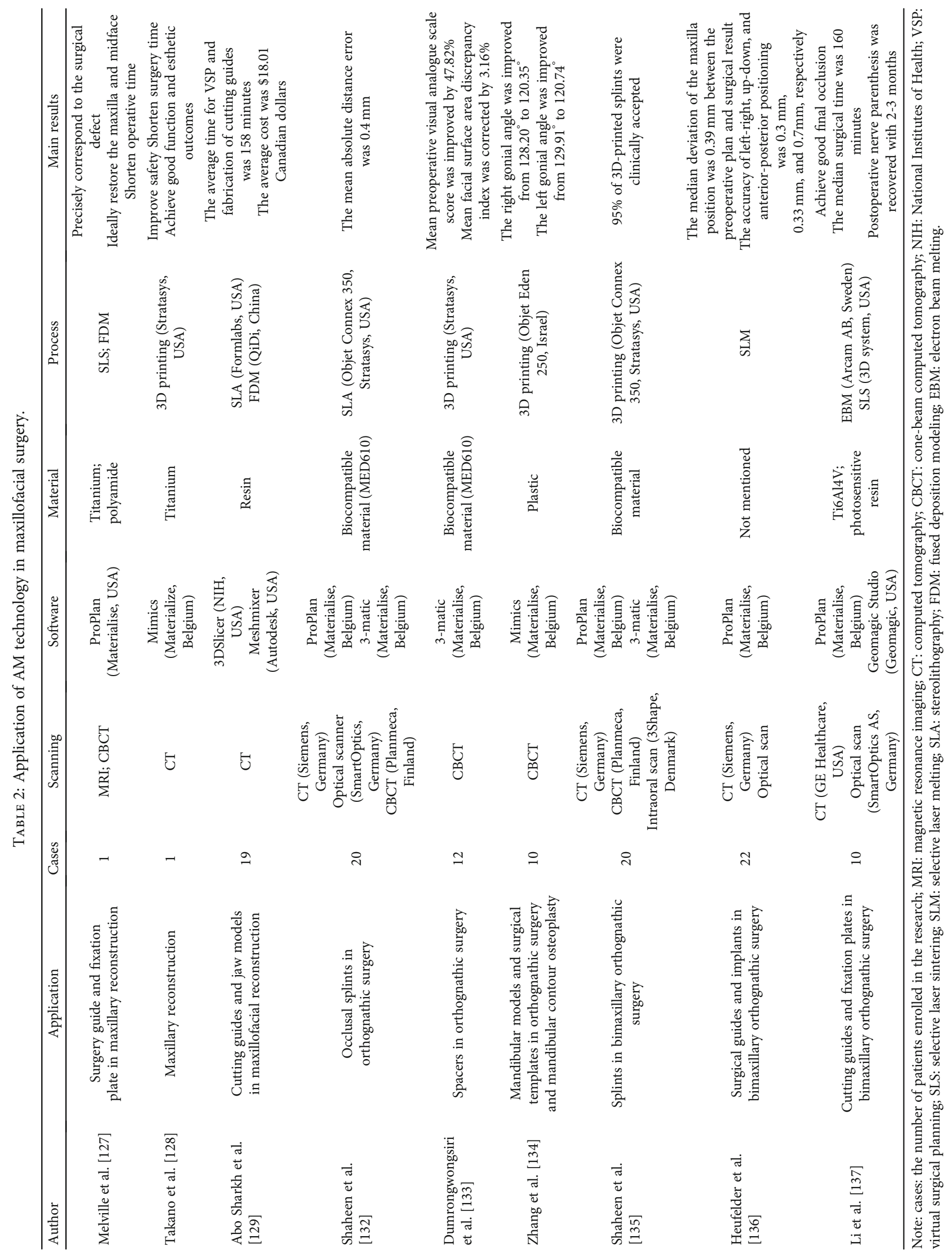




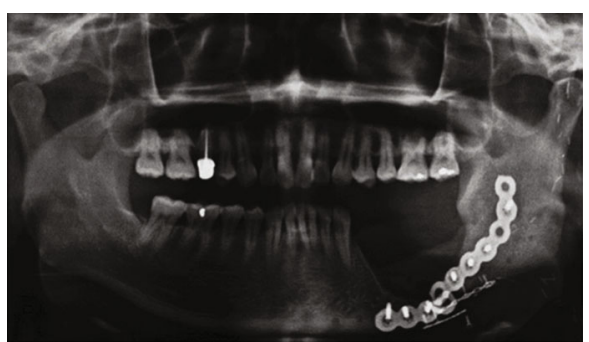

(a)

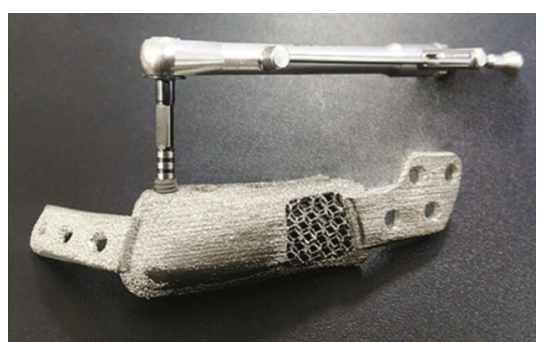

(b)

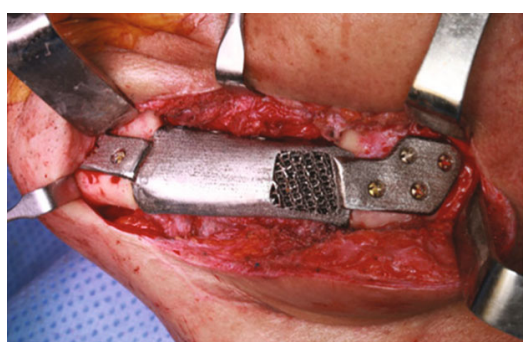

(c)

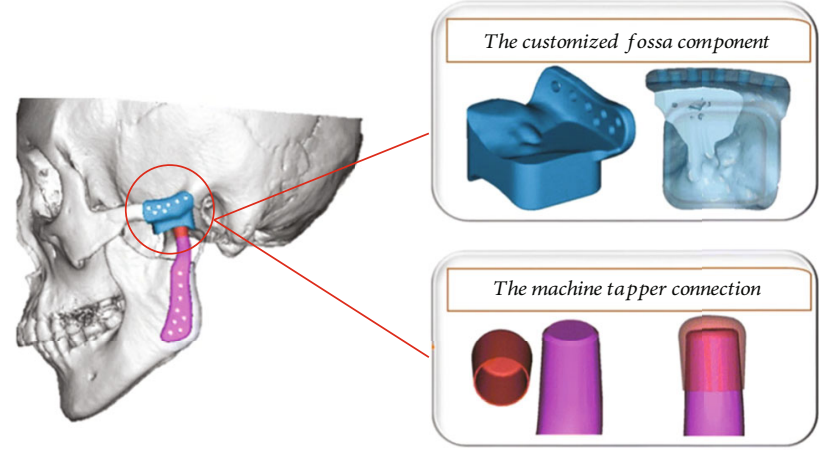

(d)

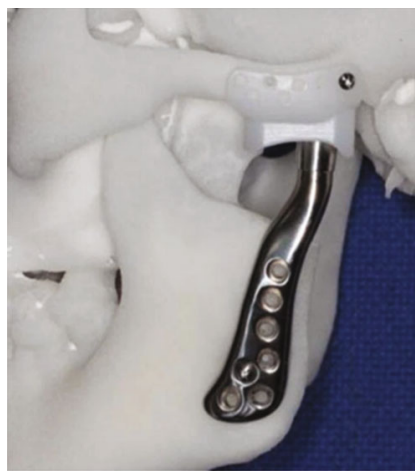

(e)

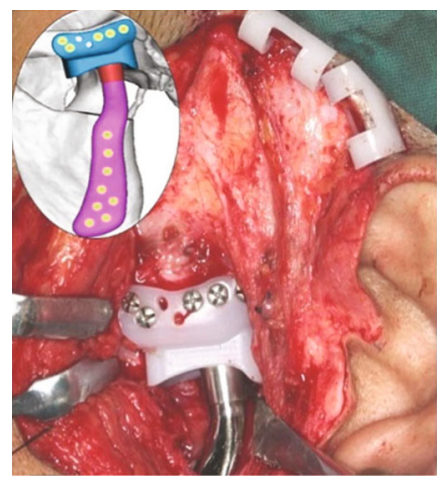

(f)

FIGURE 5: Panoramic radiograph demonstrated huge defect of the left mandible due to osteoradionecrosis (a); a titanium mandibular substitute with premounted dental implant fixtures manufactured by SLM (b) was employed to restore the bony defect (c). Reprinted from [130]. Customized temporomandibular joint (TMJ) prosthesis comprised of the fossa, condylar head, and mandibular handle components (d); the novel TMJ prosthesis can precisely match the Chinese patient's TMJ anatomy (e); the lateral view of a fixed TMJ prosthesis during a surgical procedure (f). Reprinted from [131].

In the 21st century, AM technology is more and more widely used in orthognathic surgery measurement [132]. There are many kinds of 3D-printed surgical guiding templates such as repositioning guides, osteotomy, and predrilling guides.

Dumrongwongsiri et al. used the 3D-printed Le Fort I spacers to guide maxilla-mandibular repositioning for 12 patients with facial asymmetry and malocclusion. The average time for preoperative simulation, design, and printing of these spacers was 2.5 hours. The average cost was 40 dollars per space. All the patients were satisfied with postoperative facial symmetry and occlusion [133]. Wang et al. applied a 3Dprinted mandible model and surgical templates to simultaneously perform orthognathic and mandibular contour osteoplasty for treating mandibular protrusion [134]. Shaheen et al. and Heufelder et al. proposed an optimized protocol using 3D planning-printing for bimaxillary orthognathic surgery. $95 \%$ of 3D-printed splints were clinically accepted [135]. The median deviation of the maxilla position was $0.39 \mathrm{~mm}$ between the preoperative plan and surgical result [136]. Li et al. evaluated a customized orthognathic surgical guide for splint-less bimaxillary surgery. The largest root-mean square deviations for maxillary dental arch, mandibular arch, mandibular body, and proximal segments were all below $1.1 \mathrm{~mm}$ and $2.82^{\circ}$. The median surgical time was 160 minutes. All patients achieved good final occlusion [137]. The personalized orthognathic surgical splint is accurate and effective for the sake of patients and surgeons (Figure 6) [138].

\subsection{AM Technology in Denture Implantation (Table 3)}

4.2.1. Implantation. Denture implantation is a widely accepted and prevailing treatment modality to replace lost 


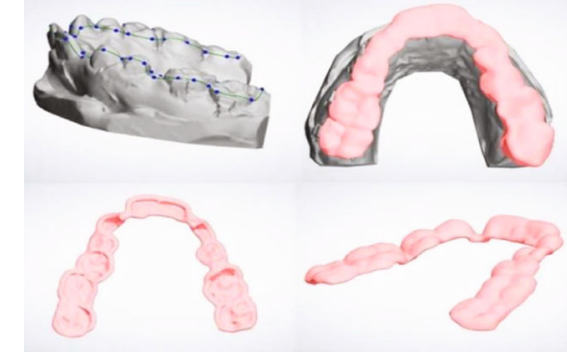

(a)

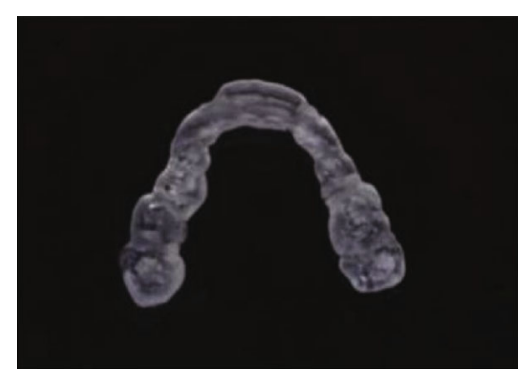

(b)

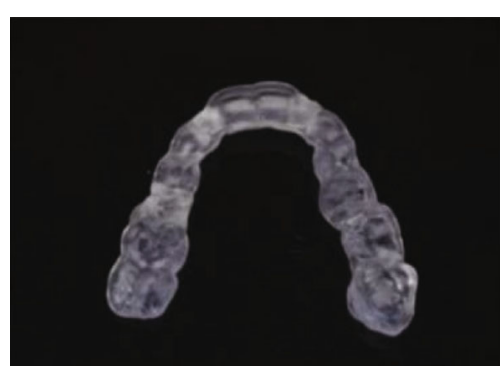

(c)

FIgURE 6: The surgical splint for orthodontic treatment can be designed via CAD software (a); thereafter, SLA technology and biocompatible photosensitive resin were employed to print this splint with sophisticated features (b, c). Reprinted from [138].

teeth. Titanium alloys are commonly used materials in dental implants due to their excellent chemical stability and biocompatibility [139]. However, the stress shielding effect caused by the mismatch of elastic modulus between the bone and titanium implant may lead to bone loss adjacent to implants [140]. Recently, AM has gained great attention for fabricating complex porous implants with improved mechanical preformation to reduce the stress shielding effect and enhance the osseointegration between bones and the implant $[58,141]$. Depending on the variation of porosity and pore size, the elastic modulus and compressive strength of the printed titanium or titanium alloy implants can coincide with those of human cortical and cancellous bone [142]. Besides, AM technology is suitable for patients whose bone mass is inadequate and implants need to avoid important anatomical structures. Compared with the commercial NobelActive ${ }^{\mathrm{TM}}$ implant, the $3 \mathrm{D}$-printed porous Ti6Al4V dental implant has higher biomedical parameters and better osseointegration [143]. Customized root form dental implant fabricated by the method of EBM technology was reported to possess superior rough and porous surface texture which facilitated the implant stabilization and osseointegration [144]. Tunchel et al. [121] launched a multicenter study to check the survival and success rates of AM titanium dental implants after three-year loading (Figure 7). The results with $94.5 \%$ survival rate and $94.3 \%$ success rate display a prosperous clinical option for the restoration of single tooth gaps using AM titanium implants [121]. Mangano et al. and Figliuzzi et al. successfully placed root analogue DLMF implants into patients. After 1-year follow-up, the implants were of good functional and aesthetic integration $[145,146]$. Another 4-year follow-up research concerning DMLS mini-implant treatment in 62 patients was reported by Mangano's research group. The survival rate was $96.9 \%$. The distance between the implant shoulder and the first visible bone-implant contact (DIB) was $0.38 \mathrm{~mm}$ for 1 -year follow-up and $0.62 \mathrm{~mm}$ for 4-year follow-up [147].

In addition to the implants, the implant templates are widely processed by $3 \mathrm{D}$ printing. Mangano et al. used 3Dprinted templates for guiding the denture implant in 20 patients partially edentulous. $96.4 \%$ of the templates were steady and suitable for clinical use [120]. Recently, Derksen et al. have conducted a prospective cohort study to evaluate the accuracy of 3D-printed templates in guiding implant position. Data comparisons were based on CBCT and intraoral scanning. The mean angular deviation was $2.72^{\circ}$, and the mean deviations at the implant's entry point and apex were, respectively, $0.75 \mathrm{~mm}$ and $1.06 \mathrm{~mm}$. Multiple factors such as the implant's length and cortical interference may affect the accuracy [148].

4.2.2. Transplantation. Transplantation, in terms of autotransplantation and allogenic tooth transplantation, is an old technique but is not widespread in dental clinics. With the development of AM technology, this old technique shows a new life. A custom-made implant drill was fabricated by the direct metal laser sintering $3 \mathrm{D}$ printing system. The allogenic tooth transplantation can be well-fitted in the recipient's alveolar bone using this $3 \mathrm{D}$-printed drill. Periapical radiographs showed that the inflammatory and replacement resorption were stable at 4-month follow-up after the transplantation. This deemed low-cost modality inspires future researches concerning AM technology for tooth transplantation which reduces bone loss and improves the implant stability [149]. In a very recent case report, 3Dprinted templates were also applied to autotransplantation with good clinical and radiologic results after 2-year follow-up [150]. Tooth transplantation could be an economic solution for patients by saving costs from an implant, abutment, and crown. In the future, more studies are inspired into this little researched field with the help of AM technology.

\subsection{AM Technology in Prosthodontics}

4.3.1. Fixed Partial Dentures. Due to the complex and delicate anatomical structure in the oral cavity, the denture made by traditional impression methods and traditional restoration techniques is still inadequate. Dental digital impression technology combined with AM technology is expected to improve the accuracy of fixed restorations. Compared with the subtractive technique such as milling, the amount of materials used in AM is less, with almost no material loss [151]. AM can mainly be used to make personalized metal inner crowns, full crowns, interim crowns, and fixed bridges [152]. A single-unit crown by AM technology may be done in as little as approximately 20 minutes; the printed crown can be easily separated from the supports and rapidly cemented [153]. A good fitness is crucial to ensure the mechanical stability and health of surrounding soft tissue 


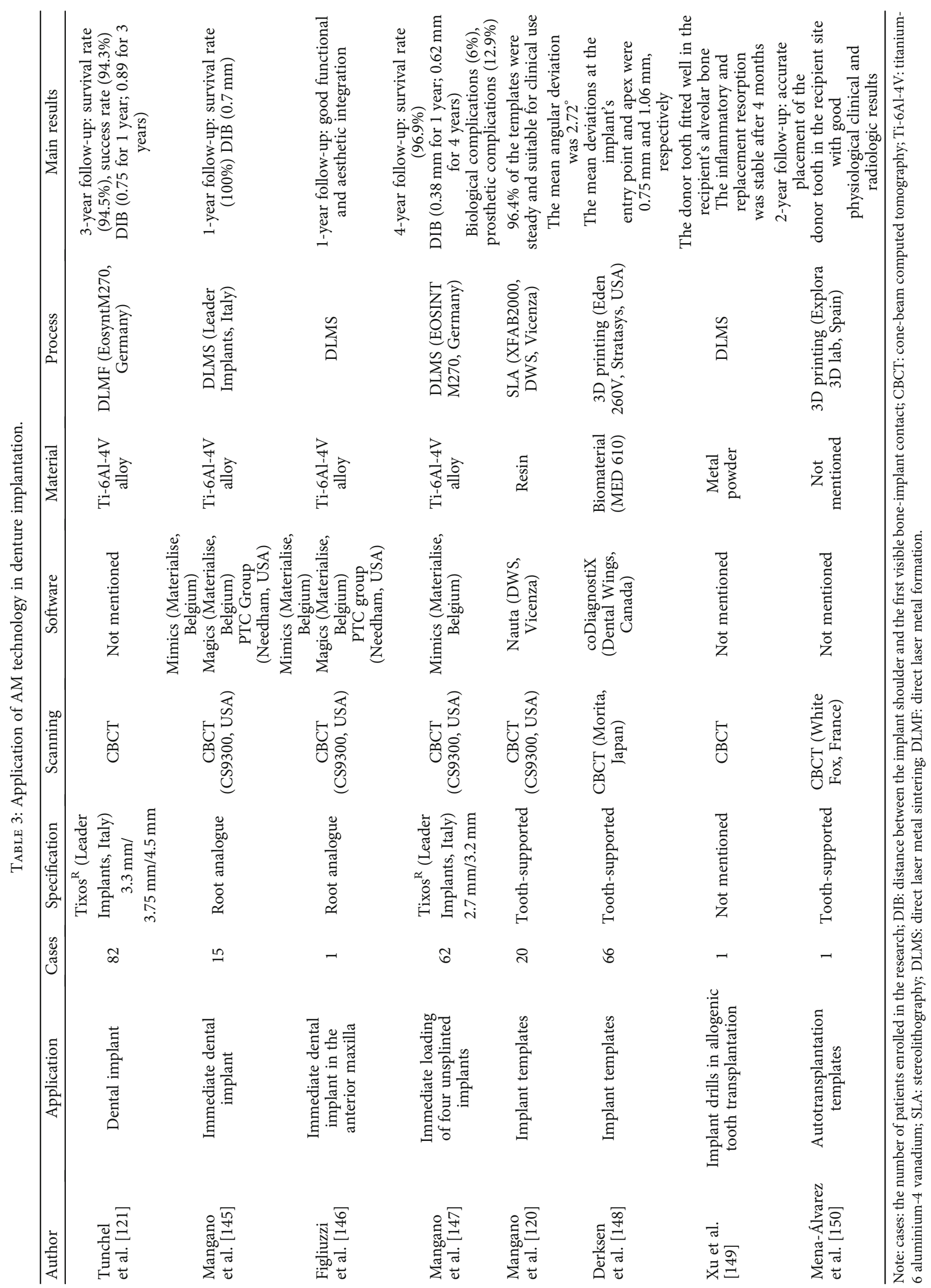



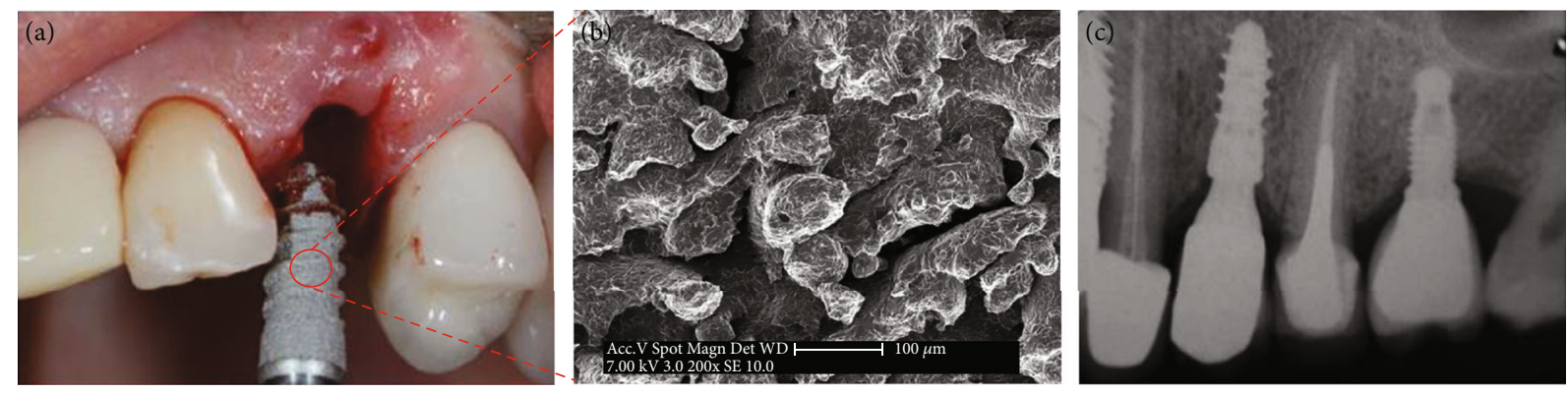

Figure 7: A commercialized 3D-printed Ti6Al4V implant (Tixos ${ }^{\circledR}$, Leader Implants, Italy) was going to be inserted in the socket (a); the surface of this printed implant consisted of tremendous grooves with 14.6 to $152.5 \mu \mathrm{m}$ in width and 21.4 to $102.4 \mu \mathrm{m}$ in depth (b); the printed dental implant possessed satisfactory osteointegration after 3 years of functional loading due to its rough surface (c). Reprinted from [121].

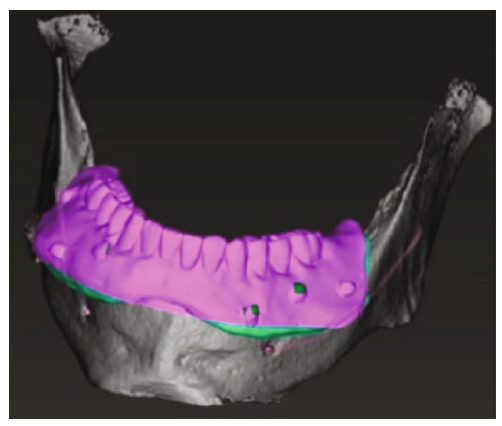

(a)

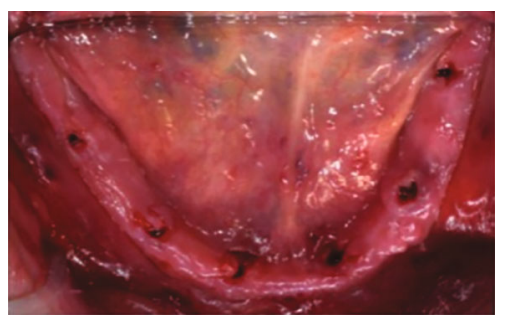

(d)

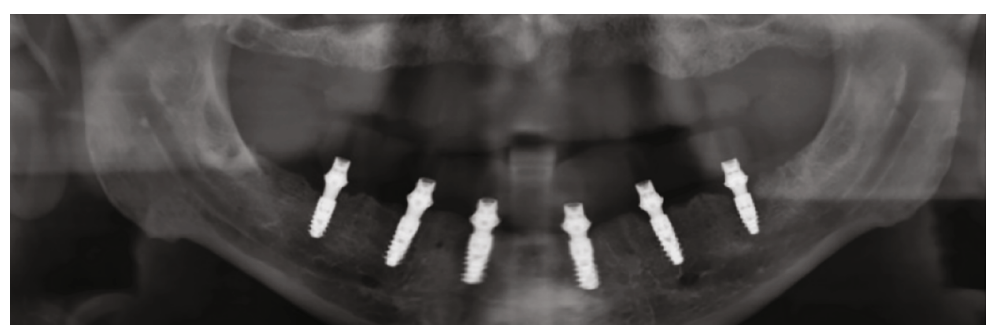

(g)

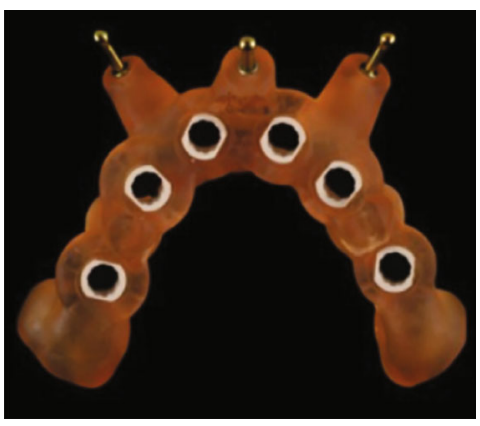

(b)

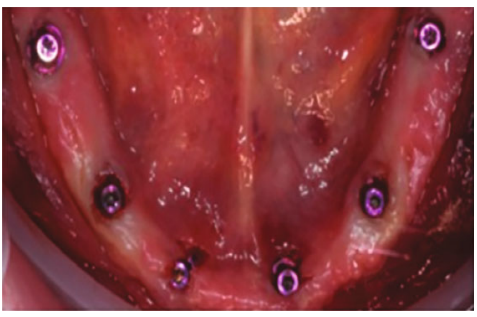

(e)

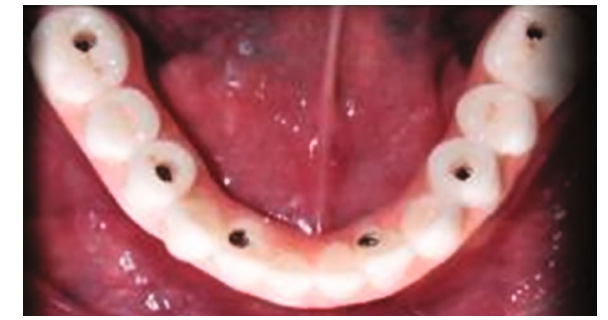

(h)

Figure 8: An implant-supported 3D-printed fixed denture was designed via CAD software (a). Meanwhile, a surgical stent was also printed (b) and used to guide the insertion of implants (c-f); the panoramic X-ray showed that the implants were well positioned (g); the printed fixed denture was subsequently delivered to the patient (h). Reprinted from [157].

[154]. The fitness of the 3D-printed metal inner crown and the prepared tooth is significantly better than that of the traditional casting metal crown [119]. Alharbi et al. found that the marginal and internal gaps of 3D-printed interim restoration were lower than those of milled restorations [155]. By optimizing the printing parameters such as laser light intensity and printing orientation for each individual material, the accuracy of AM dental crowns would be greatly improved [153]. Taken together, the application of AM technology in fixed denture greatly simplifies the process and improves precision as well as material utilization (Figure 8) [119, $156,157]$. At present, Germany BEGO Company has already developed the compact DLP 3D printer to process commercialized permanent single crowns, crown bridges, inlays, onlays, and veneers (https://www.bego.com/3d-printing/).

4.3.2. Removable Partial/Complete Denture. The traditional removable partial/full denture design and fabrication 


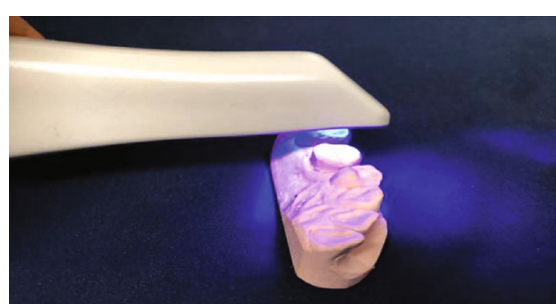

(a)

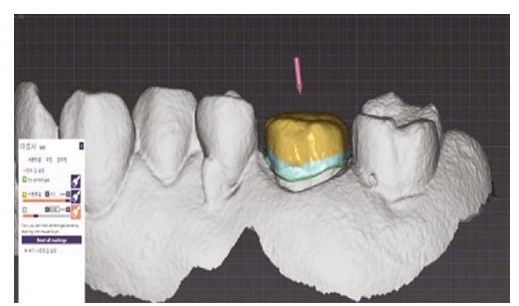

(b)

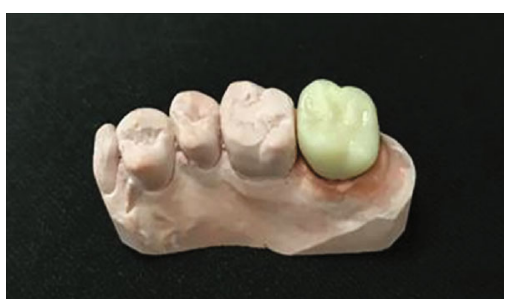

(c)

FIgURE 9: An intraoral optical scanner was used to scan the plaster model (a) to establish the digital model (b); then, the crown was designed and printed based on this digital model (c). Reprinted from [161].

commonly lead to pressure-induced mucosal pain and residual ridge resorption. Chen et al. [158] combined computeraided optimization and additive manufacturing to process the jaw model and removable partial dentures. The optimized dentures were evenly attached to the mucosa; the uniformity was improved by $63 \%$, and the contact pressure was decreased by $70 \%$, thereby reducing pressure-induced mucosal pain and alveolar bone resorption. Due to the maturity of SLM technology, denture metal alloy stents can be processed to obtain a better fitness for clinical application [159]. The computer design system and AM technology can also be used to process resin-based denture bases and denture teeth (Figure 9) [160, 161]. Compared with the traditional compression molding technology, the AM technology generates lower volume and linear shrinkage of polymethylmethacrylate resin [162]. The adaptability of the AM denture base was better than that of the milling denture base in the maxilla, especially in the pressure-bearing areas [163, 164]. However, there are still some barriers to provide a well-fit RPD structure by AM and many factors affecting its mechanical properties. Noteworthy, material properties, AM procedure, and parameters used during manufacturing are influencing the mechanical properties of products [165]. Tregerman et al. reported that SLM Co-Cr alloy frames had better organization and mechanical properties when compared with the traditional cast or milled RPD frames [166]. On the contrary, Ye et al. found that the biggest misfits occurred in the SLM RPD frameworks [167]. Misfits in both studies were in the clinically acceptable range. Moreover, the reason for above discrepancy may be attributed to the difference between cast impression and intraoral scanning [166, 167]. Fabrication fitness may be affected by scanning accuracy, numerical control program, and the method to transform the data into a $3 \mathrm{D}$ model $[168,169]$. In the future, more researches concerning the optimized parameters for AM denture should be carried out.

4.3.3. Facial Prosthesis. The traditional prosthodontic reconstruction technique is difficult to accurately reproduce the complex defects, thus affecting the repair effect. At present, the AM technology is mainly used in the fabrication of the prosthesis support and the negative mold. The main materials used are metal powder, resin, resin wax, etc. However, the silicone materials for printing are unavailable for a long period. Recently, researchers successfully developed the directly printed silicone prosthesis [170]. In addition, Fripp Design Company developed a starch powder-based 3D sys- tem for printing medical-grade silicone [171]. Unkovskiy et al. applied directly printed silicone prostheses for a 40year-old woman with a nasal defect. The interim prosthesis was acceptable; however, the position and marginal adaptation before definitive delivery of this prosthesis were difficult to evaluate [172]. Even so, this case report hints some cues in directly printed silicone prosthesis. Nuseir et al. compared a direct 3D printing workflow with the conventional workflow for a patient with a nasal defect. The total time required in $3 \mathrm{D}$-printed nose prosthesis was 310 hours, compared with 500 hours in the conventional workflow [173]. The 3D printing workflow can lead to improved prosthesis reproducibility and aesthetic features and shows a great potential in treatment for patients with facial defects.

\subsection{AM Technology in Orthodontics}

4.4.1. Digital Model. The diagnosis and treatment in orthodontics are commonly relying on plaster models. However, plaster models have high requirements on air humidity. If they are kept in places with high humidity, they are easily affected by moisture and deformed. Because of the low material strength, the plaster model is often damaged and loses its reference value in clinical practice. At present, resin models based on intraoral scanning and $3 \mathrm{D}$ printing technology have great advantages over plaster models in terms of accuracy, strength, and preservation [174].

4.4.2. Personalized Brackets. In the beginning of the 21st century, German physician Wiechmann first introduced CAD/ CAM and SLM technology to produce personalized lingual brackets $[117,118]$. A recent preliminary clinical trial showed that the AM technique could also be used to fabricate customized esthetic ceramic brackets whose mechanical parameters were similar to those of commercial ceramic brackets [175]. These 3D-printed brackets could better fit the patient's tooth surface with a good aesthetic effect and overcome some drawbacks in traditional orthodontics such as high bracket loss rate, complex indirect redounding, and time-consuming manufacturing process [175].

4.4.3. Clear Aligners. The application of clear aligners without brackets is in a rapid development stage; AM technology plays an important role in it. Briefly, the digital model of the dental jaw is reconstructed in three dimensions; then, the computer-aided diagnosis and design are used to simulate the movement of the teeth. After the plan is determined, the simulated dental jaw model is printed out using $3 \mathrm{D}$ 
printing technology; finally, the thermoforming technology is used to make an invisible appliance [176]. Currently, $3 \mathrm{D}$ printing is mainly used in the production of dentition models. The final invisible braces are still produced via traditional thermoforming technology. The printed appliance cannot be directly used in clinic due to the manufacturing accuracy, strength, and surface characteristics. A recent study showed that $3 \mathrm{D}$-printed dental resinbased clear aligners were geometrically more accurate than thermoformed aligners. And the maximum load of 3Dprinted cured dental aligners was $622 \mathrm{~N}$ for $2.93 \mathrm{~mm}$ displacement. These 3D-printed aligners were mechanically stronger than thermoformed aligners [177]. This shed light on the whole process of $3 \mathrm{D}$ printing in invisible orthodontics. Besides, Cassetta et al. had carried out an innovative orthodontic treatment method that combined computerguided piezocision and clear aligners [178]. This combined technique reduced surgical time and patient discomfort, increased periodontal safety and patient acceptability, and achieved accurate control of orthodontic movement without the risk of losing anchorage. A 23-year-old woman with moderate crowding and a 13-year-old male patient with class II malocclusion have both been treated by this combined method. Treatment duration is greatly reduced to 6-8 months. Oral health-related quality of life and periodontal indexes are both improved after 2-year follow-up $[179,180]$. However, the cases are limited and the follow-up time is not long; we need further investigation and practice to promote the use of this combined technique.

\subsection{AM Technology in Endodontics (Table 4)}

4.5.1. Root Canal Therapy. The premise of perfect root canal treatment is to establish effective access to dental pulp cavity and root canal system. The 3D-printed templates can be widely used in localization of complex root canals. Fonseca Tavares et al. applied 3D-printed templates to access calcified central incisors [181]. Maia et al. used 3D-printed guides in accessing calcified canals of the maxillary premolar and first molar. After 15- or 30-day follow-up, all patients were asymptomatic [181, 182]. Lera-Mendes et al. applied this $3 \mathrm{D}$-printed template to rapidly access the severely obliterated canals of maxillary second and third molars. After 3 months, the periapical tissue was greatly healed by the assessment of radiography [183].

Microguided endodontics is a recent accepted concept in root canal therapy which combines a small diameter bur $(0.85 \mathrm{~mm})$ with $3 \mathrm{D}$-printed surgical templates. Connert et al. were the first to use this technique on mandibular incisors [184], and Torres et al. were the first to use this technique on maxillary incisors [185]. This novel technique minimizes invasion and apical extended access in incisors with canal calcification and apical periodontitis, while it shortens operation time on the patients [186]. However, microguided endodontics might not be currently used in the posterior region due to the space limitation. There needs further elaborate designs for 3D-printed templates and burs.
4.5.2. Apical Surgery. Targeted endodontic microsurgery combined 3D-printed surgical guides with trephine burs can enhance the accuracy and efficacy of osteotomy and root-end resection, compared with traditional endodontic microsurgery [187]. Antal et al. applied SLA-fabricated surgical templates to resect $3 \mathrm{~mm}$ apical portion of the root in 11 patients with apical lesions. The mean apex removal and osteotomy depth error were $0.19 \mathrm{~mm}$ and $0.37 \mathrm{~mm}$ separately. No recurrence or complications were reported after 6-month follow-up [188]. Patients who were pathologically diagnosed as having a periapical cyst or granuloma were treated with precise osteotomy and root-end resection using a 3D-printed surgical guide. All patients were asymptomatic after 1-, 3-, or 6-month follow-up [189, 190]. Popowicz et al. reported the application of the $3 \mathrm{D}$-printed polylactide surgical guide in 2 cases that underwent root-end resection. The two patients were asymptomatic at a 7- or 8-month followup visit. Radiographic examination showed complete healing with a radiodense area around the apex of the upper left second premolar. The cortical plate at the osteotomy site was restored to the original thickness [191]. This targeted endodontic microsurgery shows great benefit in challenging anatomic cases which involve fused molar roots, the palatal root of the maxillary first/second molar, roots of the mandibular first/second premolar adjacent to the mental nerve, and roots of mandibular molars with a thick buccal bone plate [190, 192]. Further studies with a larger group of patients are necessary to obtain landmark conclusions.

4.6. AM Technology in Periodontics (Table 5). The periodontium is a complex tissue system consisting of several components like cementum, gingiva, and bone. The loss of periodontal tissue caused by periodontal disease is an irreversible process, and its regeneration has been a hot research topic in tissue engineering. The engineering of periodontal ligament (PDL), cementum, and the alveolar bone is based on a modular approach. Bioprinting using microfluidic AM technology could manufacture more highly intricate morphologies, internal structures, and architectures that accurately replicate the exact anatomical organization and biological function of periodontal tissues [122]. A solution containing keratinocytes and fibroblasts as ink components was successfully used to print out the epithelial cell rests of Malassez which are necessary for the initial stage of periodontal tissue formation [122]. Periodontal ligament stem cells (PDLSCs) show great potentials in periodontal tissue regeneration under the appropriate extracellular matrix (ECM) [193]. Gelatin methacrylate (GelMA) and poly (ethylene glycol) (PEG) dimethacrylate composition could serve as ECM materials. Cell and ECM interaction was screened by a cell-laden hydrogel array with the help of bioprinting. The cell viability and spreading area were decreased when the PEG ratio was increased [194].

Kim et al. used the compound ink of polycaprolactone (PCL) and hydroxyapatite (HA) as the raw material to align the teeth in vivo and in vitro. The normal anatomical structure of the body was restored, proving the possibility of using a dental scaffold to achieve tooth regeneration. Furthermore, cell-derived factor-1 (SDF1) and bone 


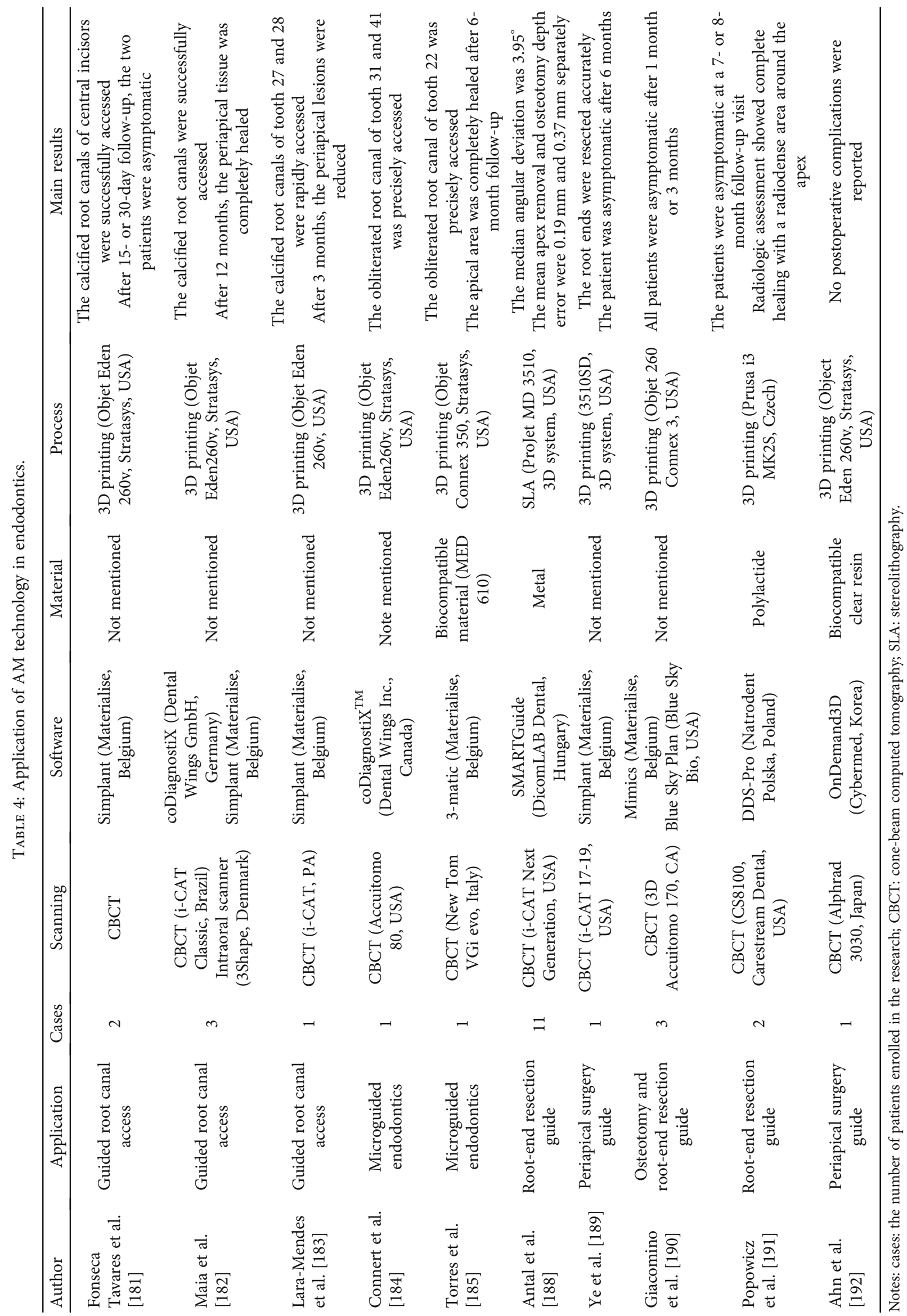




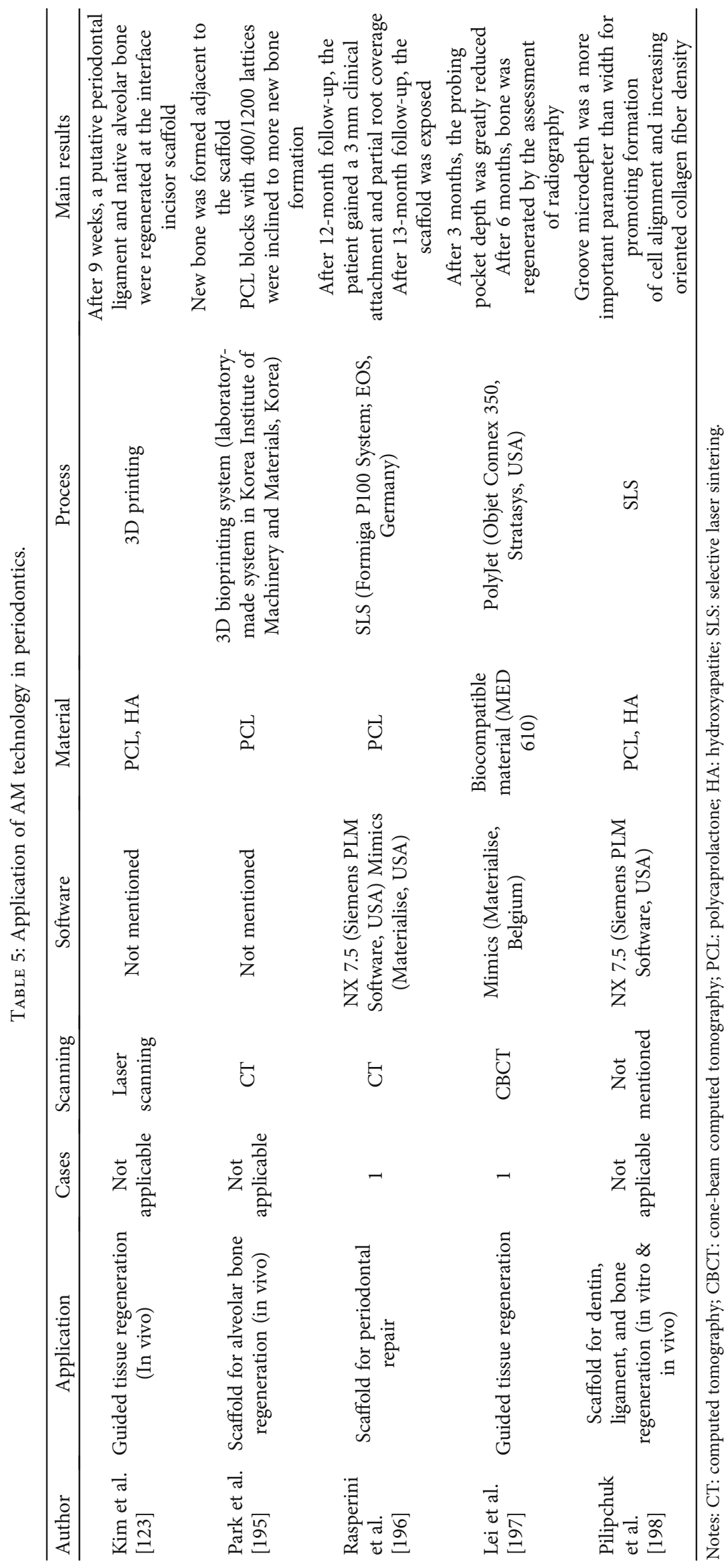


morphogenetic protein-7 (BMP7) on this porous scaffold can recruit endogenous cells with a homing effect which facilitates the generation of blood vessel-like, tooth-like, and periodontal tissues appearing at the interface between the stent and the alveolar bone [123]. Park et al. used a 3D bioprinting system to fabricate a PCL scaffold that efficiently promoted alveolar bone regeneration in a beagle defect model [195].

In clinical practice, Rasperini et al. were the first to report a personalized 3D-printed bioresorbable polymer scaffold for a 53-year-old male patient with periodontal defect. After 12month follow-up, the patient gained a $3 \mathrm{~mm}$ clinical attachment of periodontal tissue and partial root coverage. However, at the 13-month follow-up visit, the scaffold was exposed and larger dehiscence was observed [196]. Although this case was unsuccessful in the long term, the approach gave some hints and experience for personalized oral tissue regeneration in clinical settings. Recently, Lei et al. applied a 3D-printed periodontal surgery template to guide tissue regeneration in a 36-yearold male patient with severe bone defects of the upper right lateral incisor. Advanced platelet-rich fibrin (A-PRF) and injected platelet-rich fibrin (I-PRF) from the patient's blood were mixed with Bio-Oss to form a 3D ideal shape. After a 15-month follow-up, the probing pocket depth was significantly reduced to a normal range. And the alveolar bone was regenerated at the treatment sit by the assessment of radiography [197].

Although, AM has been used extensively in guided tissue regeneration, the microlevel control of scaffold structure is limited by low resolution, material selection, and complexity [7]. Pilipchuk et al. introduced a novel strategy that combined 3D printing and micropatterning to advance the microlevel design of scaffolds. Results showed that the groove microdepth of the scaffold was a more important parameter than the width for promoting formation of cell alignment and increasing oriented collagen fiber density. This technique could efficiently achieve the formation of multiple tissues such as alveolar bone, cementum, and collagenous PDL-like tissue [198]. With the advancement of materials and biofabrication technologies, tissue engineering might progress into complex functional $3 \mathrm{D}$ organs in the future [199].

\section{Conclusions and Challenges}

AM technology is based on a digital model, layered scanning, and layer-by-layer stacking forming, and by stacking points, lines, surfaces, and bodies of layer materials, a nontraditional processing technology quickly produces three-dimensional objects. Compared with traditional technology, AM has some advantages. First, this technology dramatically reduces the duration of treatment. Secondly, the satisfaction degree and comfort level of patients are improved, and the patients can enjoy the convenience brought by personalized treatment and precision medicine. Thirdly, it has greatly improved the working efficiency of clinicians. Currently, it is widely used in maxillofacial surgery, denture implantation, prosthetics, orthodontics, endodontics, and periodontics [200-202].

With the increased clinical demand, it is imperative to transit printing from simple materials to specific biomaterials with physiological activities and functions [203]. In the future, AM should be more inclined to tissue regeneration, such as degradable biological scaffolds, reconstruction of tissue and organ structures, and permanent replacements in vivo. Despite the advantages of personalization and diversified printing materials, there are still some challenges in the development of AM technology.

(1) The accuracy of 3D printing software, biomechanical properties of raw materials, and resolution of the 3D printer are crucial parameters that affect the quality of printed objects in the field of medicine and health care. Therefore, it is urgent to deepen the research on the manufacturing process and optimize the $3 \mathrm{D}$ software, materials, and equipment

(2) The microprinter used in dental medicine can really realize in-house/chairside operation. However, the accuracy of $3 \mathrm{D}$ printing equipment as well as its intelligence needs to be further improved

(3) The application of SLM technology to process removable partial denture is mature, but there is still insufficient research on the postprocessing technology that greatly impedes the large-scale application of SLM technology

(4) In the application of tissue engineering scaffolds, the optimal degradation rate, mechanical properties, porosity, and pore size of bone tissue engineering scaffolds are still inconclusive [204]. There are few biodegradable materials applied in tissue engineering, and the current $3 \mathrm{D}$ printer resolution is in the micron level that has not reached the nanolevel of the jawbone. Therefore, it is necessary to increase the resolution of the $3 \mathrm{D}$ printer to improve the scaffold function

(5) Due to the complex functions of tissues and organs, it may still take a long time to explore the cell sources and extracellular matrix types, as well as their interaction in the bioprinting [205]. Besides, the printing time will affect the cell activity. In order to speed up the printing, the printing pressure or energy intensity is commonly increased, but this will in turn damage the cells inside the stent, thereby resulting in impaired graft function [206]. The two facets should be weighed to make a reasonable choice. In addition to technical issues, bioprinting also has safety, ethics, and legal issues. These issues need to be considered during development

(6) The expensive cost and high application threshold hinder further development of AM. Although the price of $3 \mathrm{D}$ printers has been gradually declining in recent years, 3D printers with good quality are still expensive. There also needs high investment in related supporting CT, MRI equipment, and computer-aided design software. In addition, the efficient use of equipment and software requires specialized technical training and multidisciplinary technical personnel division and cooperation 
(7) With the integration of multiple disciplines, AM technology will play a more important role in the diagnosis and treatment of dentistry diseases. Therefore, to establish a thorough and mature collaboration system is urgent

(8) Emerging concept of 4D printing (3D plus time) [207] that accurately simulates the dynamic transformation of native tissues may remedy the shortcomings of $3 \mathrm{D}$ bioprinting. More researches are required to get new breakthrough in tissue regeneration using AM technology

\section{Data Availability}

No data were used to support this study.

\section{Disclosure}

This paper was submitted to a preprint server [208].

\section{Conflicts of Interest}

The authors declare that there are no conflicts of interests regarding the publication of this paper.

\section{Acknowledgments}

The authors thank the members of their research group for their hard work. This work was financially supported by the National Natural Science Foundation of China (81860480), Youth Science Fund Project of Science and Technology Department of Jiangxi Province (grant number 20181BAB215022), and Young Teachers Research and Development Fund Project of Nanchang University (grant number 4209-16100009-PY201818).

\section{References}

[1] N. Guo and M. C. Leu, "Additive manufacturing: technology, applications and research needs," Frontiers of Mechanical Engineering, vol. 8, no. 3, pp. 215-243, 2013.

[2] ASTM, ASTM F2792-12 Standard terminology for additive manufacturing technologies, ASTM International, West Conshohocken, PA, 2012.

[3] ISO/ASTM 52921: 2013 (E) Standard Terminology for Additive Manufacturing-Coordinate Systems and Test Methodologies, 2013.

[4] M. P. Chhaya, P. S. P. Poh, E. R. Balmayor, M. van Griensven, J. T. Schantz, and D. W. Hutmacher, "Additive manufacturing in biomedical sciences and the need for definitions and norms," Expert Review of Medical Devices, vol. 12, no. 5, pp. 537-543, 2015.

[5] H. Yang, P. Rao, T. Simpson et al., "Six-sigma quality management of additive manufacturing," Proceedings of the IEEE. Institute of Electrical and Electronics Engineers, vol. 109, no. 4, pp. 347-376, 2021.

[6] D. Gu, X. Shi, R. Poprawe, D. L. Bourell, R. Setchi, and J. Zhu, "Material-structure-performance integrated laser-metal additive manufacturing," Science, vol. 372, no. 6545, 2021.
[7] M. E. Prendergast and J. A. Burdick, "Recent advances in enabling technologies in 3D printing for precision medicine," Advanced Materials, vol. 32, no. 13, 2020.

[8] A. Mumith, M. Thomas, Z. Shah, M. Coathup, and G. Blunn, "Additive manufacturing," The bone \& joint journal, vol. 100B, no. 4, pp. 455-460, 2018.

[9] E. Guzzi and M. Tibbitt, "Additive manufacturing of precision biomaterials," Advanced materials, vol. 32, no. 13, 2020.

[10] S. Bose, D. Ke, H. Sahasrabudhe, and A. Bandyopadhyay, "Additive manufacturing of biomaterials," Progress in materials science, vol. 93, pp. 45-111, 2018.

[11] F. Mangano, C. Mangano, A. Piattelli, and G. Iezzi, "Histological evidence of the osseointegration of fractured direct metal laser sintering implants retrieved after 5 years of function," BioMed Research International, vol. 2017, Article ID 9732136, 7 pages, 2017.

[12] D. Anssari Moin, W. Derksen, J. P. Verweij, R. van Merkesteyn, and D. Wismeijer, "A novel approach for computerassisted template-guided autotransplantation of teeth with custom 3D designed/printed surgical tooling. An ex vivo proof of concept," Journal of Oral and Maxillofacial Surgery, vol. 74, no. 5, pp. 895-902, 2016.

[13] A. Dawood, B. M. Marti, V. Sauret-Jackson, and A. Darwood, "3D printing in dentistry," British Dental Journal, vol. 219, no. 11, pp. 521-529, 2015.

[14] M. Kasparova, L. Grafova, P. Dvorak et al., "Possibility of reconstruction of dental plaster cast from $3 \mathrm{D}$ digital study models," BioMedical Engineering OnLine, vol. 12, no. 1, p. $49,2013$.

[15] A. Bhargav, V. Sanjairaj, V. Rosa, L. W. Feng, and J. Fuh YH, "Applications of additive manufacturing in dentistry: a review," Journal of biomedical materials research. Part B, Applied biomaterials, vol. 106, no. 5, pp. 2058-2064, 2018.

[16] I. Campioni, I. Cacciotti, and N. Gupta, "Additive manufacturing of reconstruction devices for maxillofacial surgery: design and accuracy assessment of a mandibular plate prototype," Annali Dell Istituto Superiore Di Sanita, vol. 56, no. 1, pp. 10-18, 2020.

[17] I. H. Kim, S. R. Singer, and M. Mupparapu, "Review of cone beam computed tomography guidelines in North America," Quintessence International, vol. 50, no. 2, pp. 136-145, 2019.

[18] C. W. HULL, Apparatus for production of three-dimensional objects by stereolithography, Google Patents, 1986.

[19] C. W. HULL, Method for production of three-dimensional objects by stereolithography, Google Patents, 1990.

[20] C. R. Deckard, Method and apparatus for producing parts by selective sintering, Google Patents, 1989.

[21] S. S. Crump, Apparatus and method for creating threedimensional objects, Google Patents, 1992.

[22] V. Mironov, N. Reis, and B. Derby, "Review: bioprinting: a beginning," Tissue Engineering, vol. 12, no. 4, pp. 631-634, 2006.

[23] P. Thayer, H. Martinez, and E. Gatenholm, "History and trends of 3D bioprinting," Methods in Molecular Biology, vol. 2140, pp. 3-18, 2020.

[24] G. Mazza, W. al-Akkad, K. Rombouts, and M. Pinzani, "Liver tissue engineering: from implantable tissue to whole organ engineering," Hepatology Communications, vol. 2, no. 2, pp. 131-141, 2018.

[25] M. Haude, H. Ince, A. Abizaid et al., "Safety and performance of the second-generation drug-eluting absorbable metal 
scaffold in patients with de-novo coronary artery lesions (BIOSOLVE-II): 6 month results of a prospective, multicentre, non-randomised, first-in-man trial," Lancet, vol. 387, no. 10013, pp. 31-39, 2016.

[26] F. Rengier, A. Mehndiratta, H. von Tengg-Kobligk et al., "3D printing based on imaging data: review of medical applications," International journal of computer assisted radiology and surgery, vol. 5, no. 4, pp. 335-341, 2010.

[27] M. Cui, H. Pan, Y. Su et al., "Opportunities and challenges of three-dimensional printing technology in pharmaceutical formulation development," Acta pharmaceutica Sinica. B, vol. 11, no. 8, pp. 2488-2504, 2021.

[28] F. D. D. Neves, T. D. A. P. N. Carneiro, C. J. Do Prado et al., "Micrometric precision of prosthetic dental crowns obtained by optical scanning and computer-aided designing/computer-aided manufacturing system," Journal of biomedical optics, vol. 19, no. 8, article 088003, 2014.

[29] T. Matsuda, K. Kurahashi, N. Maeda, T. Goto, and T. Ichikawa, "Geometric assessment of imaging methods for complete denture form: comparisons among cone-beam computed tomography, desktop dental scanning, and handheld optical scanning," Journal of prosthodontic research, vol. 64, no. 4, pp. 485-489, 2020.

[30] A. Ball, P. Job, and A. Walker, "SEM-microphotogrammetry, a new take on an old method for generating high-resolution 3D models from SEM images," Journal of microscopy, vol. 267, no. 2, pp. 214-226, 2017.

[31] T. Bücking, E. R. Hill, J. L. Robertson, E. Maneas, A. A. Plumb, and D. I. Nikitichev, "From medical imaging data to 3D printed anatomical models," PloS one, vol. 12, no. 5, article $\mathrm{e} 0178540,2017$.

[32] B. Vandenberghe, "The crucial role of imaging in digital dentistry," Dental materials: official publication of the Academy of Dental Materials, vol. 36, no. 5, pp. 581-591, 2020.

[33] A. Marro, T. Bandukwala, and W. Mak, "Three-dimensional printing and medical imaging: a review of the methods and applications," Curr Probl Diagn Radiol, vol. 45, no. 1, pp. 29, 2016.

[34] M. Yuan, D. C. Tsai, S. C. Chang et al., "The risk of cataract associated with repeated head and neck CT studies: a nationwide population-based study," AJR. American journal of roentgenology, vol. 201, no. 3, pp. 626-630, 2013.

[35] K. Eley, S. R. Watt-Smith, F. Sheerin, and S. J. Golding, ""Black bone" MRI: a potential alternative to CT with threedimensional reconstruction of the craniofacial skeleton in the diagnosis of craniosynostosis," European radiology, vol. 24, no. 10, pp. 2417-2426, 2014.

[36] K. Eley and G. Delso, "Automated 3D MRI rendering of the craniofacial skeleton: using ZTE to drive the segmentation of black bone and FIESTA-C images," Neuroradiology, vol. 63, no. 1, pp. 91-98, 2021.

[37] K. Eley and G. Delso, "Automated segmentation of the craniofacial skeleton with "black bone" magnetic resonance imaging," The Journal of craniofacial surgery, vol. 31, no. 4, pp. 1015-1017, 2020.

[38] T. Kamio, M. Suzuki, R. Asaumi, and T. Kawai, "DICOM segmentation and STL creation for 3D printing: a process and software package comparison for osseous anatomy," $3 D$ printing in medicine, vol. 6, no. 1, p. 17, 2020.

[39] J. Pucci, B. R. Christophe, J. A. Sisti, and E. S. Connolly Jr., "Three-dimensional printing: technologies, applications, and limitations in neurosurgery," Biotechnology advances, vol. 35, no. 5, pp. 521-529, 2017.

[40] A. Ganguli, G. J. Pagan-Diaz, L. Grant et al., "3D printing for preoperative planning and surgical training: a review," Biomedical microdevices, vol. 20, no. 3, 2018.

[41] L. Ebert, M. Thali, and S. Ross, "Getting in touch-3D printing in forensic imaging," Forensic science international, vol. 211, no. 1-3, pp. e1-e6, 2011.

[42] E. Huotilainen, R. Jaanimets, J. Valášek et al., "Inaccuracies in additive manufactured medical skull models caused by the DICOM to STL conversion process," Journal of craniomaxillo-facial surgery: official publication of the European Association for Cranio-Maxillo-Facial Surgery, vol. 42, no. 5, pp. e259-e265, 2014.

[43] T. DebRoy, T. Mukherjee, J. O. Milewski et al., "Scientific, technological and economic issues in metal printing and their solutions," Nature materials, vol. 18, no. 10, pp. 1026-1032, 2019.

[44] D. Khorsandi, A. Fahimipour, P. Abasian et al., "3D and 4D printing in dentistry and maxillofacial surgery: printing techniques, materials, and applications," Acta biomaterialia, vol. 122, pp. 26-49, 2021.

[45] K. Bordji, "Evaluation of the effect of three surface treatments on the biocompatibility of $316 \mathrm{~L}$ stainless steel using human differentiated cells," Biomaterials, vol. 17, no. 5, pp. 491500, 1996.

[46] J. A. Disegi and L. Eschbach, "Stainless steel in bone surgery," Injury, vol. 31, Suppl 4, pp. D2-D6, 2000.

[47] M. Talha, C. Behera, and O. Sinha, "A review on nickel-free nitrogen containing austenitic stainless steels for biomedical applications," Materials science \& engineering. C, Materials for biological applications, vol. 33, no. 7, pp. 3563-3575, 2013.

[48] R. Asri, W. S. W. Harun, M. Samykano et al., "Corrosion and surface modification on biocompatible metals: a review," Materials science \& engineering. C, Materials for biological applications, vol. 77, pp. 1261-1274, 2017.

[49] V. P. Mantripragada, B. Lecka-Czernik, N. A. Ebraheim, and A. C. Jayasuriya, "An overview of recent advances in designing orthopedic and craniofacial implants," Journal of Biomedical Materials Research Part A, vol. 101, no. 11, pp. 33493364, 2013.

[50] R. A. Lueck, "Development of an open pore metallic implant to permit attachment to bone," Surgery Forum, vol. 20, pp. 456-457, 1969.

[51] D. A. Hollander, M. von Walter, T. Wirtz et al., "Structural, mechanical and in vitro characterization of individually structured Ti-6Al-4V produced by direct laser forming," Biomaterials, vol. 27, no. 7, pp. 955-963, 2006.

[52] N. Chanchareonsook, H. Tideman, S. Lee, S. J. Hollister, C. Flanagan, and J. A. Jansen, "Mandibular reconstruction with a bioactive-coated cementless Ti6Al4V modular endoprosthesis in Macaca fascicularis," International Journal of Oral \& Maxillofacial Surgery, vol. 43, no. 6, pp. 758-768, 2014.

[53] A. Revathi, A. D. Borrás, A. I. Muñoz, C. Richard, and G. Manivasagam, "Degradation mechanisms and future challenges of titanium and its alloys for dental implant applications in oral environment," Materials Science \& Engineering C-Materials for Biological Applications, vol. 76, pp. 13541368, 2017.

[54] M. Monjo, C. Petzold, J. M. Ramis, S. P. Lyngstadaas, and J. E. Ellingsen, "In vitro osteogenic properties of two dental 
implant surfaces," International Journal of Biomaterials, vol. 2012, 14 pages, 2012.

[55] M. Degidi, D. Nardi, and A. Piattelli, "10-year follow-up of immediately loaded implants with TiUnite porous anodized surface," Clinical Implant Dentistry and Related Research, vol. 14, no. 6, pp. 828-838, 2012.

[56] D. L. Cochran, J. M. Jackson, J. P. Bernard et al., “A 5-year prospective multicenter study of early loaded titanium implants with a sandblasted and acid-etched surface," International Journal of Oral \& Maxillofacial Implants, vol. 26, no. 6, pp. 1324-1332, 2011.

[57] S. Van Bael, "The effect of pore geometry on the in vitro biological behavior of human periosteum-derived cells seeded on selective laser-melted Ti6Al4V bone scaffolds," Acta Biomaterialia, vol. 8, no. 7, pp. 2824-2834, 2012.

[58] T. Traini, C. Mangano, R. L. Sammons, F. Mangano, A. Macchi, and A. Piattelli, "Direct laser metal sintering as a new approach to fabrication of an isoelastic functionally graded material for manufacture of porous titanium dental implants," Dental materials, vol. 24, no. 11, pp. 1525-1533, 2008.

[59] L. F. Velasquez-Garcia and Y. Kornbluth, "Biomedical applications of metal 3D printing," Annu Rev Biomed Eng, vol. 23, no. 1, pp. 307-338, 2021.

[60] Y. Okazaki and E. Gotoh, "Comparison of fatigue strengths of biocompatible Ti-15Zr-4Nb-4Ta alloy and other titanium materials," Materials Science and Engineering: C, vol. 31, no. 2, pp. 325-333, 2011.

[61] C. Veiga, J. P. Davim, and A. Loureiro, "Properties and applications of titanium alloys: brief review," Reviews on Advanced Materials Science, vol. 32, pp. 133-148, 2012.

[62] F. Trevisan, F. Calignano, A. Aversa et al., "Additive manufacturing of titanium alloys in the biomedical field: processes, properties and applications," Journal of Applied Biomaterials \& Functional Materials, vol. 16, no. 2, pp. 57-67, 2018.

[63] X. X. Xin, N. Xiang, J. Chen, and B. Wei, "In vitro biocompatibility of Co-Cr alloy fabricated by selective laser melting or traditional casting techniques," Materials Letters, vol. 88, pp. 101-103, 2012.

[64] A. Zadpoor, "Additively manufactured porous metallic biomaterials," Journal of materials chemistry. B, vol. 7, no. 26, pp. 4088-4117, 2019.

[65] X. Zhang, G. Fang, S. Leeflang, A. A. Zadpoor, and J. Zhou, "Topological design, permeability and mechanical behavior of additively manufactured functionally graded porous metallic biomaterials," Acta biomaterialia, vol. 84, pp. 437452, 2019.

[66] P. Ginestra, R. M. Ferraro, K. Zohar-Hauber, A. Abeni, S. Giliani, and E. Ceretti, "Selective laser melting and electron beam melting of Ti6Al4V for orthopedic applications: a comparative study on the applied building direction," Materials (Basel, Switzerland), vol. 13, no. 23, p. 5584, 2020.

[67] A. Zadpoor, "Mechanical performance of additively manufactured meta-biomaterials," Acta biomaterialia, vol. 85, pp. 41-59, 2019.

[68] G. Yu, Z. Li, Y. Hua et al., “The effects of post heat Treatment on the microstructural and mechanical properties of an additive-manufactured porous titanium alloy," Materials (Basel, Switzerland), vol. 13, no. 3, p. 593, 2020.

[69] S. Ahmadi, R. Kumar, E. V. Borisov et al., "From microstructural design to surface engineering: a tailored approach for improving fatigue life of additively manufactured meta-biomaterials," Acta biomaterialia, vol. 83, pp. 153-166, 2019.

[70] R. Depprich, H. Zipprich, M. Ommerborn et al., "Osseointegration of zirconia implants compared with titanium: an in vivo study," Head \& Face Medicine, vol. 4, no. 1, 2008.

[71] R. Goffard, T. Sforza, A. Clarinval et al., "Additive manufacturing of biocompatible ceramics," Advances in Production Engineering \& Management, vol. 8, no. 2, pp. 96-106, 2013.

[72] A. Ghazanfari, W. Li, M. C. Leu, J. L. Watts, and G. E. Hilmas, "Additive manufacturing and mechanical characterization of high density fully stabilized zirconia," Ceramics International, vol. 43, no. 8, pp. 6082-6088, 2017.

[73] K. Shahzad, J. Deckers, Z. Zhang, J. P. Kruth, and J. Vleugels, "Additive manufacturing of zirconia parts by indirect selective laser sintering," Journal of the European Ceramic Society, vol. 34, no. 1, pp. 81-89, 2014.

[74] J. A. Schönherr, S. Baumgartner, M. Hartmann, and J. Stampfl, "Stereolithographic additive manufacturing of high precision glass ceramic parts," Materials, vol. 13, no. 7, p. 1492, 2020.

[75] M. Hoffman, S. H. Cho, and N. K. Bansal, "Interproximal distance analysis of stereolithographic casts made by CADCAM technology: an in vitro study," The Journal of Prosthetic Dentistry, vol. 118, no. 5, pp. 624-630, 2017.

[76] J. W. Jung, H. Lee, J. M. Hong et al., "A new method of fabricating a blend scaffold using an indirect three-dimensional printing technique," Biofabrication, vol. 7, no. 4, article 045003, 2015.

[77] E. Tolba, X. Wang, M. Ackermann et al., "In situ polyphosphate nanoparticle formation in hybrid poly (vinyl alcohol)/karaya gum hydrogels: a porous scaffold inducing infiltration of mesenchymal stem cells," Advanced Science, vol. 6, no. 2, 2019.

[78] Y. Wang, L. Xi, B. Zhang et al., "Bioresorbable hydrogels prepared by photo-initiated crosslinking of diacrylated PTMCPEG-PTMC triblock copolymers as potential carrier of antitumor drugs," Saudi Pharmaceutical Journal, vol. 28, no. 3, pp. 290-299, 2020.

[79] M. H. Asim, S. Silberhumer, I. Shahzadi, A. Jalil, B. Matuszczak, and A. Bernkop-Schnürch, "S-protected thiolated hyaluronic acid: In-situ crosslinking hydrogels for 3D cell culture scaffold," Carbohydrate Polymers, vol. 237, article 116092, 2020.

[80] Q. Feng, J. Xu, K. Zhang et al., "Dynamic and cell-infiltratable hydrogels as injectable carrier of therapeutic cells and drugs for treating challenging bone defects," ACS Central Science, vol. 5, no. 3, pp. 440-450, 2019.

[81] K. Yue, G. Trujillo-de Santiago, M. M. Alvarez, A. Tamayol, N. Annabi, and A. Khademhosseini, "Synthesis, properties, and biomedical applications of gelatin methacryloyl (GelMA) hydrogels," Biomaterials, vol. 73, pp. 254-271, 2015.

[82] B. Klotz, D. Gawlitta, A. J. W. P. Rosenberg, J. Malda, and F. P. W. Melchels, "Gelatin-methacryloyl hydrogels: towards biofabrication-based tissue repair," Trends in biotechnology, vol. 34, no. 5, pp. 394-407, 2016.

[83] J. A. Burdick and G. D. Prestwich, "Hyaluronic acid hydrogels for biomedical applications," Advanced Materials, vol. 23, no. 12, pp. H41-H56, 2011.

[84] J. A. Burdick, C. Chung, X. Jia, M. A. Randolph, and R. Langer, "Controlled degradation and mechanical behavior 
of photopolymerized hyaluronic acid networks," Biomacromolecules, vol. 6, no. 1, pp. 386-391, 2005.

[85] M. T. Poldervaart, B. Goversen, M. de Ruijter et al., "3D bioprinting of methacrylated hyaluronic acid (MeHA) hydrogel with intrinsic osteogenicity," PLoS One, vol. 12, no. 6, article e0177628, 2017.

[86] A. Lee, A. R. Hudson, D. J. Shiwarski et al., "3D bioprinting of collagen to rebuild components of the human heart," Science (New York, N.Y.), vol. 365, no. 6452, pp. 482-487, 2019.

[87] T. Hinton, Q. Jallerat, R. N. Palchesko et al., “Three-dimensional printing of complex biological structures by freeform reversible embedding of suspended hydrogels," Science advances, vol. 1, no. 9, article e1500758, 2015.

[88] B. Grigoryan, S. J. Paulsen, D. C. Corbett et al., "Multivascular networks and functional intravascular topologies within biocompatible hydrogels," Science (New York, N.Y.), vol. 364, no. 6439, pp. 458-464, 2019.

[89] F. P. Melchels, J. Feijen, and D. W. Grijpma, "A review on stereolithography and its applications in biomedical engineering," Biomaterials, vol. 31, no. 24, pp. 6121-6130, 2010.

[90] M. Bedell, A. M. Navara, Y. du, S. Zhang, and A. G. Mikos, "Polymeric systems for bioprinting," Chemical reviews, vol. 120, no. 19, pp. 10744-10792, 2020.

[91] S. F. Shirazi, S. Gharehkhani, M. Mehrali et al., "A review on powder-based additive manufacturing for tissue engineering: selective laser sintering and inkjet 3D printing," Science and Technology of Advanced Materials, vol. 16, no. 3, article 033502, 2015.

[92] P. K. Gokuldoss, S. Kolla, and J. Eckert, "Additive manufacturing processes: selective laser melting, electron beam melting and binder jetting-selection guidelines," Materials, vol. 10, no. 6, p. 672, 2017.

[93] H. Kim, D. Lee, S. Young Lee et al., "Denture flask fabrication using fused deposition modeling three-dimensional printing," Journal of Prosthodontic Research, vol. 64, no. 2, pp. 231-234, 2020.

[94] E. Carlier, S. Marquette, C. Peerboom et al., "Investigation of the parameters used in fused deposition modeling of poly (lactic acid) to optimize 3D printing sessions," International Journal of Pharmaceutics, vol. 565, pp. 367-377, 2019.

[95] J. Barrios-Muriel, F. Romero-Sánchez, F. J. Alonso-Sánchez, and D. Rodríguez Salgado, "Advances in orthotic and prosthetic manufacturing: a technology review," Materials, vol. 13, no. 2, 2020.

[96] Y. Liu, P. di, Y. Zhao, Q. Hao, J. Tian, and H. Cui, “Accuracy of multi-implant impressions using 3D-printing custom trays and splinting versus conventional techniques for complete arches," The International Journal of Oral \& Maxillofacial Implants, vol. 34, no. 4, pp. 1007-1014, 2019.

[97] B. T. Goh and K. H. Teoh, "Orbital implant placement using a computer-aided design and manufacturing (CAD/CAM) stereolithographic surgical template protocol," International Journal of Oral and Maxillofacial Surgery, vol. 44, no. 5, pp. 642-648, 2015.

[98] B. Soundararajan, D. Sofia, D. Barletta, and M. Poletto, "Review on modeling techniques for powder bed fusion processes based on physical principles," Additive Manufacturing, vol. 47, 2021.

[99] L. Murr, "Open-cellular metal implant design and fabrication for biomechanical compatibility with bone using electron beam melting," Journal of the Mechanical Behavior of Biomedical Materials, vol. 76, pp. 164-177, 2017.

[100] M. Revilla-León, L. Ceballos, I. Martínez-Klemm, and M. Özcan, "Discrepancy of complete-arch titanium frameworks manufactured using selective laser melting and electron beam melting additive manufacturing technologies," The Journal of Prosthetic Dentistry, vol. 120, no. 6, pp. 942947, 2018.

[101] T. Scharowsky, V. Juechter, R. F. Singer, and C. Körner, "Influence of the scanning strategy on the microstructure and mechanical properties in selective electron beam melting of Ti-6Al-4V," Advanced Engineering Materials, vol. 17, no. 11, pp. 1573-1578, 2015.

[102] D. Lee, S. Lee, H. Kim, and C. Park, "A hybrid dental model concept utilizing fused deposition modeling and digital light processing 3D printing," The International journal of prosthodontics, vol. 33, no. 2, pp. 229-231, 2020.

[103] R. Rebong, K. T. Stewart, A. Utreja, and A. A. Ghoneima, "Accuracy of three-dimensional dental resin models created by fused deposition modeling, stereolithography, and polyjet prototype technologies: a comparative study," The Angle Orthodontist, vol. 88, no. 3, pp. 363-369, 2018.

[104] H. Yang, W. R. Leow, T. Wang et al., "3D printed photoresponsive devices based on shape memory composites," Advanced Materials, vol. 29, no. 33, 2017.

[105] S. Deng, J. Wu, M. D. Dickey, Q. Zhao, and T. Xie, "Rapid open-air digital light 3D printing of thermoplastic polymer," Advanced Materials, vol. 31, no. 39, 2019.

[106] I. Zein, D. W. Hutmacher, K. C. Tan, and S. H. Teoh, "Fused deposition modeling of novel scaffold architectures for tissue engineering applications," Biomaterials, vol. 23, no. 4, pp. 1169-1185, 2002.

[107] W. Choi, K. S. Hwang, H. J. Kwon et al., "Rapid development of dual porous poly(lactic acid) foam using fused deposition modeling (FDM) 3D printing for medical scaffold application," Materials Science \& Engineering: C, vol. 110, 2020.

[108] N. Scoutaris, S. Ross, and D. Douroumis, "Current trends on medical and pharmaceutical applications of inkjet printing technology," Pharmaceutical Research, vol. 33, no. 8, pp. 1799-1816, 2016.

[109] T. Boland, T. Xu, B. Damon, and X. Cui, “Application of inkjet printing to tissue engineering," Biotechnology Journal, vol. 1, no. 9, pp. 910-917, 2006.

[110] M. A. Heinrich, W. Liu, A. Jimenez et al., "3D bioprinting: from benches to translational applications," Small, vol. 15, no. 23, 2019.

[111] P. Tack, J. Victor, P. Gemmel, and L. Annemans, "3D-printing techniques in a medical setting: a systematic literature review," BioMedical Engineering OnLine, vol. 15, no. 1, 2016.

[112] M. Di Prima, J. Coburn, D. Hwang, J. Kelly, A. Khairuzzaman, and L. Ricles, "Additively manufactured medical products - the FDA perspective," $3 D$ Printing in Medicine, vol. 2, no. 1, 2016.

[113] C. Höhne and M. Schmitter, "3D printed teeth for the preclinical education of dental students," Journal of Dental Education, vol. 83, no. 9, pp. 1100-1106, 2019.

[114] P. Boonsiriphant, Z. al-Salihi, J. A. Holloway, and G. B. Schneider, "The use of 3D printed tooth preparation to assist in teaching and learning in preclinical fixed prosthodontics courses," Journal of Prosthodontics, vol. 28, no. 2, pp. e545e547, 2019. 
[115] H. H. Lin, D. Lonic, and L. J. Lo, “3D printing in orthognathic surgery - A literature review," Journal of the Formosan Medical Association, vol. 117, no. 7, pp. 547-558, 2018.

[116] C. Li, Y. Cai, W. Wang et al., "Combined application of virtual surgery and $3 \mathrm{D}$ printing technology in postoperative reconstruction of head and neck cancers," BMC Surgery, vol. 19, no. 1, 2019.

[117] D. Wiechmann, "A new bracket system for lingual orthodontic treatment. Part 1: theoretical background and development," Journal of Orofacial Orthopedics, vol. 63, no. 3, pp. 234-245, 2002.

[118] D. Wiechmann, "A new bracket system for lingual orthodontic Treatment," Journal of Orofacial Orthopedics, vol. 64, no. 5, pp. 372-388, 2003.

[119] M. M. Methani, M. Revilla-Leon, and A. Zandinejad, "The potential of additive manufacturing technologies and their processing parameters for the fabrication of all-ceramic crowns: a review," Journal of Esthetic and Restorative Dentistry, vol. 32, no. 2, pp. 182-192, 2020.

[120] F. G. Mangano, U. Hauschild, and O. Admakin, "Full inoffice guided surgery with open selective tooth-supported templates: a prospective clinical study on 20 patients," International Journal of Environmental Research and Public Health, vol. 15, no. 11, 2018.

[121] S. Tunchel, A. Blay, R. Kolerman, E. Mijiritsky, and J. A. Shibli, "3D printing/additive manufacturing single titanium dental implants: a prospective multicenter study with 3 years of follow-up," International Journal of Dentistry, vol. 2016, Article ID 8590971, 9 pages, 2016.

[122] D. W. Green, J. S. Lee, and H. S. Jung, "Small-scale fabrication of biomimetic structures for periodontal regeneration," Frontiers in Physiology, vol. 7, 2016.

[123] K. Kim, C. H. Lee, B. K. Kim, and J. J. Mao, “Anatomically shaped tooth and periodontal regeneration by cell homing," Journal of Dental Research, vol. 89, no. 8, pp. 842-847, 2010.

[124] S. Heid and A. R. Boccaccini, "Advancing bioinks for 3D bioprinting using reactive fillers: a review," Acta Biomaterialia, vol. 113, pp. 1-22, 2020.

[125] H. M. Klein, W. Schneider, G. Alzen, E. D. Voy, and R. W. Günther, "Pediatric craniofacial surgery: comparison of milling and stereolithography for 3D model manufacturing," Pediatric Radiology, vol. 22, no. 6, pp. 458-460, 1992.

[126] P. S. D'Urso, T. M. Barker, W. J. Earwaker et al., "Stereolithographic biomodelling in cranio-maxillofacial surgery: a prospective trial," Journal of Cranio-Maxillo-Facial Surgery, vol. 27, no. 1, pp. 30-37, 1999.

[127] J. C. Melville, C. S. Manis, J. W. Shum, and D. Alsuwied, "Single-Unit 3D-Printed Titanium Reconstruction Plate for Maxillary Reconstruction: The Evolution of Surgical Reconstruction for Maxillary Defects -A Case Report and Review of Current Techniques," Journal of Oral and Maxillofacial Surgery, vol. 77, no. 4, pp. 874.e1-874e13, 2019.

[128] M. Takano, K. Sugahara, M. Koyachi et al., "Maxillary reconstruction using tunneling flap technique with 3D custommade titanium mesh plate and particulate cancellous bone and marrow graft: a case report," Maxillofacial Plastic and Reconstructive Surgery, vol. 41, no. 1, 2019.

[129] H. Abo Sharkh and N. Makhoul, "In-house surgeon-led virtual surgical planning for maxillofacial reconstruction," Journal of Oral and Maxillofacial Surgery, vol. 78, no. 4, pp. 651660, 2020.
[130] J. Park, M. Odkhuu, S. Cho, J. Li, B. Y. Park, and J. W. Kim, "3D-printed titanium implant with pre-mounted dental implants for mandible reconstruction: a case report," Maxillofacial Plastic and Reconstructive Surgery, vol. 42, no. 1, 2020.

[131] J. Zheng, X. Z. Chen, W. B. Jiang, S. Y. Zhang, M. J. Chen, and C. Yang, "An innovative total temporomandibular joint prosthesis with customized design and 3D printing additive fabrication: a prospective clinical study," Journal of Translational Medicine, vol. 17, no. 1, 2019.

[132] E. Shaheen, Y. Sun, R. Jacobs, and C. Politis, “Three-dimensional printed final occlusal splint for orthognathic surgery: design and validation," International Journal of Oral and Maxillofacial Surgery, vol. 46, no. 1, pp. 67-71, 2017.

[133] S. Dumrongwongsiri, H. H. Lin, L. S. Niu, and L. J. Lo, "Customized three-dimensional printing spacers for bone positioning in orthognathic surgery for correction and prevention of facial asymmetry," Plastic and Reconstructive Surgery, vol. 144, no. 2, pp. 246e-251e, 2019.

[134] Y. Zhang, X. Sun, L. Wang, K. Chen, X. Wang, and G. Wu, "Simultaneous orthognathic surgery and mandibular contour osteoplasty for treating mandibular protrusion with high gonial angle," The Journal of Craniofacial Surgery, vol. 31, 2020.

[135] E. Shaheen, R. Coopman, R. Jacobs, and C. Politis, "Optimized 3D virtually planned intermediate splints for bimaxillary orthognathic surgery: a clinical validation study in 20 patients," Journal of Cranio-Maxillo-Facial Surgery, vol. 46, no. 9, pp. 1441-1447, 2018.

[136] M. Heufelder, F. Wilde, S. Pietzka et al., "Clinical accuracy of waferless maxillary positioning using customized surgical guides and patient specific osteosynthesis in bimaxillary orthognathic surgery," Journal of Cranio-Maxillo-Facial Surgery, vol. 45, no. 9, pp. 1578-1585, 2017.

[137] B. Li, S. Shen, W. Jiang et al., "A new approach of splint-less orthognathic surgery using a personalized orthognathic surgical guide system: a preliminary study," International Journal of Oral and Maxillofacial Surgery, vol. 46, no. 10, pp. 1298-1305, 2017.

[138] G. Palazzo, V. Ronsivalle, G. Oteri et al., "Comparison between additive and subtractive CAD-CAM technique to produce orthognathic surgical splints: a personalized approach," Journal of Personalized Medicine, vol. 10, no. 4, p. 273, 2020.

[139] X. Liu, S. Chen, J. K. H. Tsoi, and J. P. Matinlinna, "Binary titanium alloys as dental implant materials-a review," Regenerative Biomaterials, vol. 4, no. 5, pp. 315-323, 2017.

[140] G. Mehdi, A. Belarbi, B. Mansouri, and Z. Azari, "Numerical study of effect of elastomeric stress absorbers on stress reduction in bone-dental implant interface," Journal of Applied Oral Science: Revista FOB, vol. 23, no. 1, pp. 87-93, 2015.

[141] C. C. Huang, M. J. Li, P. I. Tsai et al., "Novel design of additive manufactured hollow porous implants," Dental Materials, vol. 36, no. 11, pp. 1437-1451, 2020.

[142] M. Surmeneva, R. A. Surmenev, E. A. Chudinova et al., "Fabrication of multiple-layered gradient cellular metal scaffold via electron beam melting for segmental bone reconstruction," Materials \& Design, vol. 133, pp. 195-204, 2017.

[143] C. C. Tu, P. I. Tsai, S. Y. Chen, M. Y. Kuo, J. S. Sun, and J. Z. Chang, "3D laser-printed porous $\mathrm{Ti}_{6} \mathrm{Al}_{4} \mathrm{~V}$ dental implants for compromised bone support," Journal of the Formosan Medical Association, vol. 119, no. 1, pp. 420-429, 2020. 
[144] R. Ramakrishnaiah, A. A. al kheraif, A. Mohammad et al., "Preliminary fabrication and characterization of electron beam melted Ti-6Al-4V customized dental implant," Saudi Journal of Biological Sciences, vol. 24, no. 4, pp. 787-796, 2017.

[145] F. G. Mangano, M. De Franco, A. Caprioglio, A. Macchi, A. Piattelli, and C. Mangano, "Immediate, non-submerged, root-analogue direct laser metal sintering (DLMS) implants: a 1-year prospective study on 15 patients," Lasers in Medical Science, vol. 29, no. 4, pp. 1321-1328, 2014.

[146] M. Figliuzzi, A. Giudice, C. Rengo, and L. Fortunato, "A direct metal laser sintering (DMLS) root analogue implant placed in the anterior maxilla. Case report," Annali Italiani di Chirurgia, vol. 8, 2019.

[147] F. G. Mangano, A. Caprioglio, L. Levrini, D. Farronato, P. A. Zecca, and C. Mangano, "Immediate loading of mandibular overdentures supported by one-piece, direct metal laser sintering mini-implants: a short-term prospective clinical study," Journal of Periodontology, vol. 86, no. 2, pp. 192200, 2015.

[148] W. Derksen, D. Wismeijer, T. Flügge, B. Hassan, and A. Tahmaseb, "The accuracy of computer-guided implant surgery with tooth-supported, digitally designed drill guides based on CBCT and intraoral scanning. A prospective cohort study," Clinical Oral Implants Research, vol. 30, no. 10, pp. 1005-1015, 2019.

[149] H. D. Xu, R. J. Miron, X. X. Zhang, and Y. F. Zhang, “Allogenic tooth transplantation using $3 \mathrm{D}$ printing: a case report and review of the literature," World Journal of Clinical Cases, vol. 7, no. 17, pp. 2587-2596, 2019.

[150] J. Mena-Álvarez, E. Riad-Deglow, N. Quispe-López, C. RicoRomano, and A. Zubizarreta-Macho, "Technology at the service of surgery in a new technique of autotransplantation by guided surgery: a case report," BMC Oral Health, vol. 20, no. $1,2020$.

[151] R. van Noort, “The future of dental devices is digital," Dental Materials, vol. 28, no. 1, pp. 3-12, 2012.

[152] S. Chaturvedi, N. M. Alqahtani, M. K. Addas, and M. A. Alfarsi, "Marginal and internal fit of provisional crowns fabricated using 3D printing technology," Technology and Health Care, vol. 28, no. 6, pp. 635-642, 2020.

[153] A. Tahayeri, M. C. Morgan, A. P. Fugolin et al., "3D printed versus conventionally cured provisional crown and bridge dental materials," Dental Materials, vol. 34, no. 2, pp. 192200, 2018.

[154] C. Sampaio, K. D. Niemann, D. D. Schweitzer, R. Hirata, and P. J. Atria, "Microcomputed tomography evaluation of cement film thickness of veneers and crowns made with conventional and3Dprinted provisional materials," Journal of Esthetic and Restorative Dentistry, vol. 33, no. 3, pp. 487495, 2021.

[155] N. Alharbi, S. Alharbi, V. M. J. I. Cuijpers, R. B. Osman, and D. Wismeijer, "Three-dimensional evaluation of marginal and internal fit of 3D-printed interim restorations fabricated on different finish line designs," Journal of Prosthodontic Research, vol. 62, no. 2, pp. 218-226, 2018.

[156] M. Revilla-León, M. Meyer, and M. Özcan, "Metal additive manufacturing technologies: literature review of current status and prosthodontic applications," International journal of computerized dentistry, vol. 22, no. 1, pp. 55-67, 2019.

[157] P. Venezia, F. Torsello, V. Santomauro, V. Dibello, and R. Cavalcanti, "Full digital workflow for the treatment of an edentulous patient with guided surgery, immediate loading and 3D-printed hybrid prosthesis: the BARI technique 2.0. A case report," International Journal of Environmental Research and Public Health, vol. 16, no. 24, 2019.

[158] J. Chen, R. Ahmad, H. Suenaga et al., "Shape optimization for additive manufacturing of removable partial dentures-a new paradigm for prosthetic CAD/CAM," PLoS One, vol. 10, no. 7, 2015.

[159] M. Pordeus, J. F. Santiago Junior, H. S. Venante, R. M. Bringel da Costa, A. P. Chappuis Chocano, and V. C. Porto, "Computer-aided technology for fabricating removable partial denture frameworks: a systematic review and meta-analysis," The Journal of Prosthetic Dentistry, 2021.

[160] M. T. Kattadiyil, C. J. Goodacre, and N. Z. Baba, “CAD/CAM complete dentures: a review of two commercial fabrication systems," Journal of the California Dental Association, vol. 41, no. 6, pp. 407-416, 2013.

[161] Y. Kim, B. Y. Jung, S. S. Han, and C. W. Woo, "Accuracy evaluation of $3 \mathrm{D}$ printed interim prosthesis fabrication using a CBCT scanning based digital model," PLoS One, vol. 15, no. 10, 2020.

[162] A. Parvizi, T. Lindquist, R. Schneider, D. Williamson, D. Boyer, and D. V. Dawson, "Comparison of the dimensional accuracy of injection-molded denture base materials to that of conventional pressure-pack acrylic resin," Journal of Prosthodontics, vol. 13, no. 2, pp. 83-89, 2004.

[163] S. Yoon, K. C. Oh, S. J. Lee, J. S. Han, and H. I. Yoon, “Tissue surface adaptation of CAD-CAM maxillary and mandibular complete denture bases manufactured by digital light processing: a clinical study," The Journal of Prosthetic Dentistry, vol. 124, no. 6, pp. 682-689, 2020.

[164] H. Yoon, H. J. Hwang, C. Ohkubo, J. S. Han, and E. J. Park, "Evaluation of the trueness and tissue surface adaptation of CAD-CAM mandibular denture bases manufactured using digital light processing," The Journal of Prosthetic Dentistry, vol. 120, no. 6, pp. 919-926, 2018.

[165] N. Alharbi, D. Wismeijer, and R. Osman, "Additive manufacturing techniques in prosthodontics: where do we currently stand? A critical review," The International Journal of Prosthodontics, vol. 30, no. 5, pp. 474-484, 2017.

[166] I. Tregerman, W. Renne, A. Kelly, and D. Wilson, "Evaluation of removable partial denture frameworks fabricated using 3 different techniques," The Journal of Prosthetic Dentistry, vol. 122, no. 4, pp. 390-395, 2019.

[167] H. Ye, J. Ning, M. Li et al., "Preliminary clinical application of removable partial denture frameworks fabricated using computer-aided design and rapid prototyping techniques," The International Journal of Prosthodontics, vol. 30, no. 4, pp. 348-353, 2017.

[168] H. Hayama, K. Fueki, J. Wadachi, and N. Wakabayashi, "Trueness and precision of digital impressions obtained using an intraoral scanner with different head size in the partially edentulous mandible," Journal of Prosthodontic Research, vol. 62, no. 3, pp. 347-352, 2018.

[169] C. Arnold, J. Hey, R. Schweyen, and J. M. Setz, "Accuracy of CAD-CAM-fabricated removable partial dentures," The Journal of Prosthetic Dentistry, vol. 119, no. 4, pp. 586-592, 2018.

[170] S. K. Jindal, M. Sherriff, M. G. Waters, J. E. Smay, and T. J. Coward, "Development of a 3D printable maxillofacial silicone: part II. Optimization of moderator and thixotropic 
agent," The Journal of Prosthetic Dentistry, vol. 119, no. 2, pp. 299-304, 2018.

[171] K. Xiao, F. Zardawi, R. van Noort, and J. M. Yates, "Color reproduction for advanced manufacture of soft tissue prostheses," Journal of Dentistry, vol. 41, pp. e15-e23, 2013.

[172] A. Unkovskiy, S. Spintzyk, J. Brom, F. Huettig, and C. Keutel, "Direct 3D printing of silicone facial prostheses: a preliminary experience in digital workflow," The Journal of Prosthetic Dentistry, vol. 120, no. 2, pp. 303-308, 2018.

[173] A. Nuseir, M. M. Hatamleh, A. Alnazzawi, M. Al-Rabab'ah, B. Kamel, and E. Jaradat, "Direct 3D printing of flexible nasal prosthesis: optimized digital workflow from scan to fit," Journal of Prosthodontics, vol. 28, no. 1, pp. 10-14, 2019.

[174] S. Y. Kim, Y. S. Shin, H. D. Jung, C. J. Hwang, H. S. Baik, and J. Y. Cha, "Precision and trueness of dental models manufactured with different 3-dimensional printing techniques," American Journal of Orthodontics and Dentofacial Orthopedics, vol. 153, no. 1, pp. 144-153, 2018.

[175] L. Yang, G. Yin, X. Liao, X. Yin, and N. Ye, "A novel customized ceramic bracket for esthetic orthodontics: in vitro study," Progress in Orthodontics, vol. 20, no. 1, 2019.

[176] A. Fekonja, N. Roser, and I. Drstvensek, "Additive manufacturing in orthodontics," Materiali in Tehnologije, vol. 53, no. 2, pp. 165-169, 2019.

[177] P. Jindal, M. Juneja, F. L. Siena, D. Bajaj, and P. Breedon, "Mechanical and geometric properties of thermoformed and 3D printed clear dental aligners," American Journal of Orthodontics and Dentofacial Orthopedics, vol. 156, no. 5, pp. 694-701, 2019.

[178] M. Cassetta and M. Ivani, "The accuracy of computer-guided piezocision: a prospective clinical pilot study," International Journal of Oral and Maxillofacial Surgery, vol. 46, no. 6, pp. 756-765, 2017.

[179] M. Cassetta, R. Guarnieri, and F. Altieri, "The combined use of clear aligners and computer-guided piezocision: a case report with a 2-year follow-up," International Journal of Computerized Dentistry, vol. 23, no. 1, pp. 57-71, 2020.

[180] M. Cassetta, F. Altieri, S. Pandolfi, and M. Giansanti, "The combined use of computer-guided, minimally invasive, flapless corticotomy and clear aligners as a novel approach to moderate crowding: a case report," The Korean Journal of Orthodontics, vol. 47, no. 2, pp. 130-141, 2017.

[181] W. L. Fonseca Tavares, A. C. Diniz Viana, V. de Carvalho Machado, L. C. Feitosa Henriques, and A. P. Ribeiro Sobrinho, "Guided endodontic access of calcified anterior teeth," Journal of Endodontics, vol. 44, no. 7, pp. 1195-1199, 2018.

[182] L. M. Maia, V. de Carvalho Machado, N. R. F. A. da Silva et al., "Case reports in maxillary posterior teeth by guided endodontic access," Journal of Endodontics, vol. 45, no. 2, pp. 214-218, 2019.

[183] S. T. O. Lara-Mendes, C. . F. M. Barbosa, C. C. Santa-Rosa, and V. C. Machado, "Guided endodontic access in maxillary molars using cone-beam computed tomography and computer-aided design/computer-aided manufacturing system: a case report," Journal of Endodontics, vol. 44, no. 5, pp. 875-879, 2018.

[184] T. Connert, M. S. Zehnder, M. Amato, R. Weiger, S. Kühl, and G. Krastl, "Microguided endodontics: a method to achieve minimally invasive access cavity preparation and root canal location in mandibular incisors using a novel computer-guided technique," International Endodontic Journal, vol. 51, no. 2, pp. 247-255, 2018.

[185] A. Torres, E. Shaheen, P. Lambrechts, C. Politis, and R. Jacobs, "Microguided endodontics: a case report of a maxillary lateral incisor with pulp canal obliteration and apical periodontitis," International Endodontic Journal, vol. 52, no. 4, pp. 540-549, 2019.

[186] T. Connert, M. S. Zehnder, R. Weiger, S. Kühl, and G. Krastl, "Microguided endodontics: accuracy of a miniaturized technique for apically extended access cavity preparation in anterior teeth," Journal of Endodontics, vol. 43, no. 5, pp. 787-790, 2017.

[187] T. K. Hawkins, J. A. Wealleans, A. M. Pratt, and J. J. Ray, "Targeted endodontic microsurgery and endodontic microsurgery: a surgical simulation comparison," International Endodontic Journal, vol. 53, no. 5, pp. 715-722, 2020.

[188] M. Antal, E. Nagy, G. Braunitzer, M. Fráter, and J. Piffkó, "Accuracy and clinical safety of guided root end resection with a trephine: a case series," Head \& Face Medicine, vol. 15 , no. 1 , p. $30,2019$.

[189] S. Ye, S. Zhao, W. Wang, Q. Jiang, and X. Yang, "A novel method for periapical microsurgery with the aid of 3D technology: a case report," BMC Oral Health, vol. 18, no. 1, 2018.

[190] C. M. Giacomino, J. J. Ray, and J. A. Wealleans, “Targeted Endodontic Microsurgery: A Novel Approach to Anatomically Challenging Scenarios Using 3-dimensional-printed Guides and Trephine Burs-A Report of 3 Cases," Journal of Endodontics, vol. 44, no. 4, pp. 671-677, 2018.

[191] W. Popowicz, A. Palatynska-Ulatowska, and M. R. Kohli, "Targeted endodontic microsurgery: computed tomography-based guided stent approach with platelet-rich fibrin graft: a report of 2 cases," Journal of Endodontics, vol. 45, no. 12, pp. 1535-1542, 2019.

[192] S. Y. Ahn, N. H. Kim, S. Kim, B. Karabucak, and E. Kim, "Computer-aided design/computer-aided manufacturingguided endodontic surgery: guided osteotomy and apex localization in a mandibular molar with a thick buccal bone plate," Journal of Endodontics, vol. 44, no. 4, pp. 665-670, 2018.

[193] L. Peng, L. Ye, and X. D. Zhou, "Mesenchymal stem cells and tooth engineering," International Journal of Oral Science, vol. 1, no. 1, pp. 6-12, 2009.

[194] Y. Ma, Y. Ji, G. Huang, K. Ling, X. Zhang, and F. Xu, "Bioprinting $3 \mathrm{D}$ cell-laden hydrogel microarray for screening human periodontal ligament stem cell response to extracellular matrix," Biofabrication, vol. 7, no. 4, 2015.

[195] S. A. Park, H. J. Lee, K. S. Kim et al., "In Vivo evaluation of 3D-printed polycaprolactone scaffold implantation combined with $\beta$-TCP powder for alveolar bone augmentation in a beagle defect model," Materials, vol. 11, no. 2, 2018.

[196] G. Rasperini, S. P. Pilipchuk, C. L. Flanagan et al., "3Dprinted bioresorbable scaffold for periodontal repair," Journal of Dental Research, vol. 94, pp. 153S-157S, 2015.

[197] L. Lei, Y. Yu, T. Ke, W. Sun, and L. Chen, “The application of three-dimensional printing model and platelet-rich fibrin technology in guided tissue regeneration surgery for severe bone defects," Journal of Oral Implantology, vol. 45, no. 1, pp. 35-43, 2019.

[198] S. P. Pilipchuk, A. Monje, Y. Jiao et al., "Integration of 3D printed and micropatterned polycaprolactone scaffolds for guidance of oriented collagenous tissue formation in vivo," 
Advanced Healthcare Materials, vol. 5, no. 6, pp. 676-687, 2016.

[199] M. Yadid, H. Oved, E. Silberman, and T. Dvir, "Bioengineering approaches to treat the failing heart: from cell biology to 3D printing," Nature Reviews Cardiology, vol. 19, no. 2, pp. 83-99, 2022.

[200] M. Azuma, T. Yanagawa, N. Ishibashi-Kanno et al., "Mandibular reconstruction using plates prebent to fit rapid prototyping 3-dimensional printing models ameliorates contour deformity," Head \& Face Medicine, vol. 10, no. 1, p. 45, 2014.

[201] J. Li, Y. Hsu, E. Luo, A. Khadka, and J. Hu, "Computer-aided design and manufacturing and rapid prototyped nanoscale hydroxyapatite/polyamide (n-HA/PA) construction for condylar defect caused by mandibular angle ostectomy," Aesthetic Plastic Surgery, vol. 35, no. 4, pp. 636-640, 2011.

[202] H. Dan, C. Vaquette, A. G. Fisher et al., "The influence of cellular source on periodontal regeneration using calcium phosphate coated polycaprolactone scaffold supported cell sheets," Biomaterials, vol. 35, no. 1, pp. 113-122, 2014.

[203] S. Yildirim, S. Y. Fu, K. Kim et al., "Tooth regeneration: a revolution in stomatology and evolution in regenerative medicine," International Journal of Oral Science, vol. 3, no. 3, pp. 107-116, 2011.

[204] M. Mabrouk, H. H. Beherei, and D. B. Das, "Recent progress in the fabrication techniques of 3D scaffolds for tissue engineering," Materials Science and Engineering: C, vol. 110, 2020.

[205] R. Levato, T. Jungst, R. G. Scheuring, T. Blunk, J. Groll, and J. Malda, "From shape to function: the next step in bioprinting," Advanced Materials, vol. 32, no. 12, 2020.

[206] M. E. Pepper, V. Seshadri, T. C. Burg, K. J. L. Burg, and R. E. Groff, "Characterizing the effects of cell settling on bioprinter output," Biofabrication, vol. 4, no. 1, 2012.

[207] Q. Yang, B. Gao, and F. Xu, "Recent advances in $4 \mathrm{D}$ bioprinting," Biotechnology Journal, vol. 15, no. 1, 2020.

[208] G. Huang, F. He, L. Wan, and S. T. Pan, "Main applications and recent research progresses of additive manufacturing in dentistry," Preprints, vol. 2021, 2021. 